\title{
Strategies for Remodeling the Tumor Microenvironment Using Active Ingredients of Ginseng-A Promising Approach for Cancer Therapy
}

\begin{abstract}
Mo $\mathrm{Li}^{1,2}$, Xin Wang ${ }^{3}$, Ying Wang ${ }^{4}$, Shunchao Bao ${ }^{1}$, Qing Chang ${ }^{1}$, Linlin Liu ${ }^{1 *}$, Shuai Zhang ${ }^{5 *}$ and Liwei Sun ${ }^{6 *}$

${ }^{1}$ Department of Radiotherapy, The Second Hospital of Jilin University, Changchun, China, ${ }^{2}$ Department of Thyroid Surgery, The Second Hospital of Jilin University, Changchun, China, ${ }^{3}$ Department of Neurology, China-Japan Union Hospital of Jilin University, Changchun, China, ${ }^{4}$ Department of Breast Surgery, The Second Hospital of Jilin University, Changchun, China, Jilin Ginseng Academy, Changchun University of Chinese Medicine, Changchun, China, ${ }^{6}$ Research Center of Traditional Chinese Medicine, The Affiliated Hospital to Changchun University of Chinese Medicine, Changchun, China
\end{abstract}

OPEN ACCESS

Edited by:

Ruiwen Zhang,

University of Houston, United States

Reviewed by:

Lian Xiang Luo,

Guangdong Medical University, China

An-Sik Chung,

Korea Advanced Institute of Science and Technology, South Korea

*Correspondence: Linlin Liu

liulin/@jlu.edu.cn

Shuai Zhang

zhangs530@nenu.edu.cn Liwei Sun

sunnylilwei@163.com

Specialty section: This article was submitted to

Ethnopharmacology,

a section of the journal

Frontiers in Pharmacology

Received: 21 October 2021 Accepted: 06 December 2021 Published: 22 December 2021

Citation:

Li M, Wang $X$, Wang $Y$, Bao S, Chang $Q$, Liu L, Zhang $S$ and Sun $L$ (2021) Strategies for Remodeling the Tumor Microenvironment Using Active Ingredients of Ginseng-A Promising

Approach for Cancer Therapy.

Front. Pharmacol. 12:797634.

doi: 10.3389/fphar.2021.797634
The tumor microenvironment (TME) plays a key role in promoting the initiation and progression of tumors, leading to chemoradiotherapy resistance and immunotherapy failure. Targeting of the TME is a novel anti-tumor therapeutic approach and is currently a focus of anti-tumor research. Panax ginseng C. A. Meyer (ginseng), an ingredient of wellknown traditional Asia medicines, exerts beneficial anti-tumor effects and can regulate the TME. Here, we present a systematic review that describes the current status of research efforts to elucidate the functions and mechanisms of ginseng active components (including ginsenosides and ginseng polysaccharides) for achieving TME regulation. Ginsenosides have variety effects on TME, such as Rg3, Rd and Rk3 can inhibit tumor angiogenesis; $\mathrm{Rg} 3$, Rh2 and M4 can regulate the function of immune cells; Rg3, Rd and Rg5 can restrain the stemness of cancer stem cells. Ginseng polysaccharides (such as red ginseng acidic polysaccharides and polysaccharides extracted from ginseng berry and ginseng leaves) can regulate TME mainly by stimulating immune cells. In addition, we propose a potential mechanistic link between ginseng-associated restoration of gut microbiota and the tumor immune microenvironment. Finally, we describe recent advances for improving ginseng efficacy, including the development of a nano-drug delivery system. Taken together, this review provides novel perspectives on potential applications for ginseng active ingredients as anti-cancer adjuvants that achieve anti-cancer effects by reshaping the tumor microenvironment.

Keywords: tumor microenvironment, tumor angiogenesis, tumor stem cell, immune response, Panax ginseng (C.A. Meyer), cancer therapy

\section{INTRODUCTION}

Efforts to develop anti-cancer therapies no longer focus specifically on targeting tumor cells themselves, since cancer progression is regulated by the interaction between tumor cells and the tumor-site environment. The tumor microenvironment (TME) is a complex tumor ecosystem that are dominated by tumor and consists of tumor cells, stromal cells, immune cells, and the extracellular 
TABLE 1 | Effects of Ginsenosides on angiogenesis.

\begin{tabular}{|c|c|c|c|c|}
\hline Components & Cell/animal model & Effects & Main mechanisms & Ref. \\
\hline Ginsenoside Rg3 & $\begin{array}{l}\text { In vitro, EPCs; In vivo, Lewis lung } \\
\text { carcinoma (LLC) tumor-bearing murine } \\
\text { model }\end{array}$ & $\begin{array}{l}\text { Could suppress EPCs proliferation, migratory } \\
\text { ability and tubular formation ability in vitro, and } \\
\text { decrease number of peripheral EPCs and } \\
\text { tumor capillary in vivo }\end{array}$ & $\begin{array}{l}\text { Suppressing VEGF dependent p38 and } \\
\text { ERK signal pathways }\end{array}$ & $\begin{array}{l}\text { Kim et al. } \\
\text { (2012a) }\end{array}$ \\
\hline Ginsenoside Rg3 & $\begin{array}{l}\text { In vitro, cord blood-derived CD34 stem/ } \\
\text { progenitor cells }\end{array}$ & $\begin{array}{l}\text { Could attenuating EPC differentiation of } \\
\text { human cord blood derived CD34-positive } \\
\text { stem cells }\end{array}$ & $\begin{array}{l}\text { Inhibiting VEGF dependent Akt/eNOS } \\
\text { pathways }\end{array}$ & $\begin{array}{l}\text { Kim et al. } \\
(2012 b)\end{array}$ \\
\hline Ginsenoside Rg3 & $\begin{array}{l}\text { In vitro, colorectal cancer cells(CRC) LoVo; } \\
\text { in vivo, LoVo orthotopic xenograft murine } \\
\text { model }\end{array}$ & $\begin{array}{l}\text { Could decrease microvessel density (MVD) } \\
\text { levels }\end{array}$ & $\begin{array}{l}\text { Downregulating expression of several } \\
\text { pro-angiogenic genes }\end{array}$ & $\begin{array}{l}\text { Tang et al. } \\
(2018)\end{array}$ \\
\hline Ginsenoside Rg3 & In vitro, gastric cancer cell line BGC823 & Could inhibit expression of VEGF & Downregulating expression of HIF-a & $\begin{array}{l}\mathrm{Li} \text { and } \mathrm{Qu}, \\
\text { (2019) }\end{array}$ \\
\hline Ginsenoside Rg3 & $\begin{array}{l}\text { In vitro and in vivo, a highly metastatic } \\
\text { subline of murine B16 melanoma cells }\end{array}$ & $\begin{array}{l}\text { Could decrease the number of vessels } \\
\text { oriented toward the tumor lesions, and } \\
\text { reduce vascular endothelial cell proliferation } \\
\text { and migration }\end{array}$ & $\begin{array}{l}\text { Downregulating expression of VEGF by } \\
\text { inhibiting Akt and ERK pathways }\end{array}$ & $\begin{array}{l}\text { Meng et al. } \\
\text { (2019) }\end{array}$ \\
\hline Ginsenoside Rd & $\begin{array}{l}\text { In vitro, HUVECs; in vivo, breast cancer } \\
\text { cell line MDA-MB-231 mouse model }\end{array}$ & $\begin{array}{l}\text { Could inhibit VEGF-dependent migration, } \\
\text { vascularization and viability and angiogenesis } \\
\text { activity of HUVECs, and prevent tumor } \\
\text { angiogenesis }\end{array}$ & $\begin{array}{l}\text { Inhibiting expression of HIF- } \alpha \text { and } \\
\text { VEGFNEGFR through Akt/mTOR/ } \\
\text { p70S6K signaling pathway }\end{array}$ & $\begin{array}{l}\text { Zhang et al. } \\
(2017)\end{array}$ \\
\hline Ginsenoside Rk3 & $\begin{array}{l}\text { In vivo, human NSCLC H460 xenograft } \\
\text { mouse model, chick embryo } \\
\text { chorioallantoic membrane (CAM) model }\end{array}$ & $\begin{array}{l}\text { Could decrease the expression of endothelial } \\
\text { cell marker CD34 in tumor tissues and inhibit } \\
\text { angiogenetic activity in CAM model }\end{array}$ & Not clear & $\begin{array}{l}\text { Duan et al. } \\
\text { (2017) }\end{array}$ \\
\hline $\begin{array}{l}20(\mathrm{~S})- \\
\text { protopanaxadiol }\end{array}$ & In vitro, HUVECs & $\begin{array}{l}\text { Could induce endoplasmic reticulum stress } \\
\text { and apoptosis of HUVECs }\end{array}$ & $\begin{array}{l}\text { Inducing PERK-elF2-ATF4-CHOP } \\
\text { signaling pathway. }\end{array}$ & $\begin{array}{l}\text { Wang } X \text {. } \\
\text { et al. (2019) }\end{array}$ \\
\hline Ginsenoside Rb1 & In vitro, HUVECs & $\begin{array}{l}\text { Could suppressing the formation of } \\
\text { endothelial tube-like structures }\end{array}$ & $\begin{array}{l}\text { Increasing expression of PEDF via } \\
\text { activating PPAR }-\gamma / \text { miR-33a pathway }\end{array}$ & $\begin{array}{l}\text { Lu et al. } \\
(2017)\end{array}$ \\
\hline $\begin{array}{l}\text { Ginsenoside Ro and } \\
\text { its metabolites }\end{array}$ & In vitro, HUVECs & Could inhibit tube formation of HUVECs. & Not clear & $\begin{array}{l}\text { Zheng et al. } \\
\text { (2019) }\end{array}$ \\
\hline $\begin{array}{l}\text { Ginsenoside F1 } \\
\text { and Rh1 }\end{array}$ & $\begin{array}{l}\text { In vitro and in vivo, HUVECs and human } \\
\text { retinal microvascular endothelial } \\
\text { cells(HRMECs) }\end{array}$ & Could inhibit VEGF-induced vascular leakage & $\begin{array}{l}\text { Targeted suppressing NR4A1 } \\
\text { expression and transcriptional activity }\end{array}$ & $\begin{array}{l}\text { Kang et al. } \\
\text { (2019) }\end{array}$ \\
\hline
\end{tabular}

matrix (Wang et al., 2021; Zhang et al., 2021). The overall complexity of an anti-tumor treatment depends on interactions between the TME and tumor that support tumor growth and heterogeneity, as well as tumor invasion, metastasis, immune escape, and resistance to radiotherapy and chemotherapy (Cheng et al., 2020; Abou Khouzam et al., 2021). In view of the important role of the TME in tumor development, tumor treatment approaches have evolved from traditional measures aimed at eliminating tumor cells to multipronged comprehensive treatment measures focused on eliminating both tumor cells and the TME. Therapeutic strategies targeting the TME include enhancement of antitumor immunity, inhibition of tumor angiogenesis, administration of anti-inflammatory agents, and blockage of communication between tumor cells and the extracellular matrix (Pitt et al., 2016). A variety of drugs that target the TME are currently in widespread clinical use. For example, antibody treatments are used to enhance the anti-tumor immune response by blocking negative immunomodulatory effects on "immune checkpoints" that are induced by tumor or immunosuppressive cells within the TME. Such antibodies include anti-CTLA-4 antibodies that restore costimulatory signaling of cytotoxic T lymphocytes (CTLs) and anti-PD-1/ PD-L1 antibodies that block PD-1/PD-L1 inhibition of activated CTL function. Meanwhile, drugs targeting tumor angiogenesis are also available that include antibodies targeting the VEGF/VEGFR axis, which block tumor-site endothelial cell angiogenesis and promote vascular normalization. Therefore, targeting of the TME is a novel and promising strategy for the development of anti-tumor drugs.

Panax ginseng C.A. Meyer, known as "the king of herbs," has been used in Asian medicine for thousands of years to treat illness and was also used primarily as an energy and body balance tonic in ancient times. Nowadays, ginseng has been shown to have benefits for relieving a variety of disorders, such as inflammation, infection, fatigue, effects of aging, and cancer. Active ingredients of ginseng, such as ginsenosides and polysaccharides, have been shown to possess significant anti-tumor activities (Sun et al., 2017; Ahuja et al., 2018; Li X. et al., 2020; Guo et al., 2021). Ginsenosides induce tumor cell death by inducing initiation of programmed death pathways or inhibiting tumor proliferation by interfering with tumor cell cycle and metabolic pathways. In addition, ginsenosides effectively inhibit tumor cell invasion and metastasis, while ginseng polysaccharides have been shown to induce tumor cell apoptosis and inhibit tumor cell metastasis. Furthermore, ginseng may counter immunosuppressive TME effects by modulating immune cell differentiation and functions and regulating immune checkpoints to restore antitumor immune functions. Collectively, these results indicate that ginseng anti-tumor efficacy may depend on abilities of its 


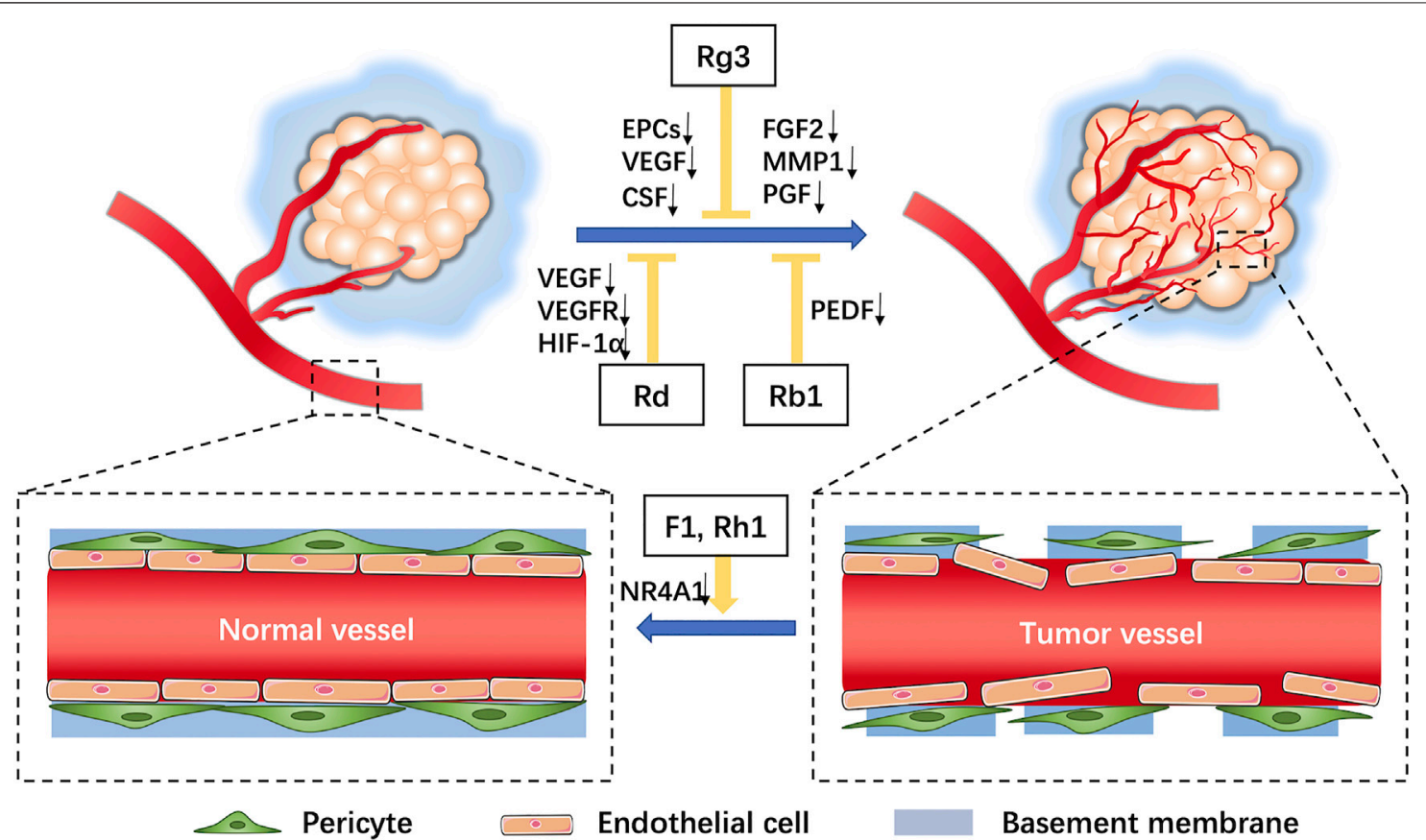

FIGURE 1 | Characteristics of tumor vessels and roles of ginsenosides on tumor angiogenesis. In the tumor microenvironment, tumor blood vessels comprise a tortuous, over-branched, and disordered vascular network structure with increased vascular permeability (increased endothelial cell gaps, loss of pericyte coverage, and incomplete basement membrane). Ginsenosides can inhibit effects of angiogenic factors on tumor angiogenesis and facilitate vascular normalization.

constituents to regulate multiple targets within the TME. In this review, molecular mechanisms underlying TME regulation by ginseng active ingredients are reviewed.

\section{THE ROLE OF GINSENOSIDES IN INHIBITING TUMOR ANGIOGENESIS}

Under normal physiological conditions, blood vessel formation is a tightly controlled process. However, during the process of tumor proliferation, the tumor-dominated microenvironment promotes aberrant angiogenesis by breaking the vascular homeostatic balance (Weis and Cheresh, 2011). A large number of pro-angiogenic and anti-angiogenic factors participate in vascular homeostasis. When these factors are in equilibrium, the vascular system remains stable and endothelial cells do not proliferate. By contrast, when the "angiogenesis switch" is turned on, the vascular homeostatic balance becomes disrupted and tips in favor of pro-angiogenesis (Hanahan and Folkman, 1996; Bergers and Benjamin, 2003; Lugano et al., 2020). Bone marrow-derived endothelial progenitor cells (EPCs) recruited by tumors participate in the pathological neovascularization and growth of early tumors by modulating the angiogenic switch (Nolan et al., 2007; Oh et al., 2007; Plummer et al., 2013; Bonfim-Silva et al., 2017; Xu et al., 2017). Moreover, hypoxic conditions, a hallmark of the TME, are closely related to initiation of tumor angiogenesis, whereby the ubiquitin-proteasome pathway of hypoxia inducible factor-1 (HIF-1) is inhibited under hypoxic conditions, which leads to intracellular HIF-1 complex accumulation that promotes initiation of transcription of pro-angiogenic genes. Proangiogenic factors and their homologous receptors effectively co-operate to promote angiogenesis within tumors during which vascular endothelial growth factor and its receptor (VEGF/ VEGFR) system play a pivotal role (Weis and Cheresh, 2005; Shibuya, 2013; Ribatti and Tamma, 2019). Furthermore, the leakage and collapse of tumor blood vessels can exacerbate hypoperfusion and hypoxia, leading to increased secretion of VEGF. Meanwhile, other angiogenesis-related factors and molecules (e.g., ANG1, FGF2, PDGF, ephrins, MMPs, etc.) may also contribute to the formation of a defective vascular network in tumors (Lugano et al., 2020) that may explain why neo-vessels in the TME possess abnormal morphology and network structure and have increased blood vessel permeability. In turn, aberrant angiogenesis supports tumor growth, invasion, and metastasis and may intensify the hypoxic microenvironment surrounding the tumor to promote tumor proliferation.

Anti-angiogenesis therapies, which mainly target the VEGF signaling pathway, have been approved for treatment of a variety of tumors (Lugano et al., 2020; Shibuya, 2013), although drug development is ongoing due to drug resistance and adverse reactions. Natural herbs such as ginseng are increasingly being viewed as potential anti-angiogenesis drugs, including various ginsenoside monomers that have been found to inhibit angiogenesis in tumors (Table 1). For example, ginsenoside Rg3 was found to inhibit EPCs differentiation, proliferation, and migration by suppressing VEGF-dependent p38/ERK and 
TABLE 2 | Effects of ginseng on innate immune cells.

\begin{tabular}{|c|c|c|c|c|}
\hline Components & Cell/animal model & Effects & Main mechanisms & Ref. \\
\hline \multicolumn{5}{|l|}{ Macrophages } \\
\hline Rg3-LPs & $\begin{array}{l}\text { In vitro and in vivo, C6 murine glioma } \\
\text { cells and tumor-bearing murine } \\
\text { models }\end{array}$ & $\begin{array}{l}\text { Could enhance PTX cytotoxicity and } \\
\text { apoptosis in C6 cells, prolong median } \\
\text { survival time of tumor-bearing mice/ } \\
\text { rats }\end{array}$ & $\begin{array}{l}\text { A synergistic effect on TAM repolarization } \\
\text { with PTX; decreasing the numbers of } \\
\text { granulocyte-like myeloid derived } \\
\text { suppressor cells in tumor } \\
\text { microenvironment }\end{array}$ & Zhu et al. (2021) \\
\hline Ginsenoside Rh2 & $\begin{array}{l}\text { In vitro, the murine macrophage-like } \\
\text { cell line RAW264.7 and NSCLC cells; } \\
\text { in vivo, LLC-bearing murine model }\end{array}$ & $\begin{array}{l}\text { Could inhibit the growth and } \\
\text { migration of human lung cancer cells }\end{array}$ & $\begin{array}{l}\text { Inducing repolarization of TAM to M1-like } \\
\text { phenotype; downregulating } \\
\text { M2 macrophages-induced secretion and } \\
\text { expression of VEGF-C, MMP2, and } \\
\text { MMP9 in NSCLC cells; decreasing the } \\
\text { VEGF-C and marker of M2-like } \\
\text { phenotype expression }\end{array}$ & Li H. et al. (2018) \\
\hline Ginsenoside Rp1 & $\begin{array}{l}\text { In vitro, the J774A. } 1 \text { macrophage } \\
\text { cells and CT26 colon cancer cells }\end{array}$ & $\begin{array}{l}\text { Could decrease the migration } \\
\text { activities of colon cancer cells and } \\
\text { prolong the survival rates of tumor- } \\
\text { bearing mice }\end{array}$ & $\begin{array}{l}\text { Inhibiting ionizing radiation enhanced } \\
\text { LPS-stimulated NO synthesis and IL-1 } \beta \\
\text { production in macrophages; } \\
\text { radioprotective effects on J774A. } 1 \text { via } \\
\text { inhibiting MAPK and Akt pathways }\end{array}$ & Baik et al. (2020) \\
\hline $\begin{array}{l}\text { Red ginseng acidic } \\
\text { polysaccharide }\end{array}$ & $\begin{array}{l}\text { In vitro and in vivo, murine melanoma } \\
\mathrm{B} 16 \text { cells and tumor-bearing model } \\
\text { of C57BL/ } 6 \text { mice }\end{array}$ & $\begin{array}{l}\text { Could enhance the tumoricidal } \\
\text { activity of murine peritoneal } \\
\text { macrophages against B16 cells }\end{array}$ & $\begin{array}{l}\text { Increasing production of IL-1, IL-6, TNF- } \\
\alpha \text { and NO via activating NF- } \mathrm{kB} \text { pathway } \\
\text { when combine with IFN- } \gamma \text { treatment }\end{array}$ & Choi et al. (2008) \\
\hline $\begin{array}{l}\text { Ginseng neutral } \\
\text { polysaccharide fraction }\end{array}$ & $\begin{array}{l}\text { Sarcoma-180 cells and tumor- } \\
\text { bearing ICR mice }\end{array}$ & Could inhibit tumor growth & $\begin{array}{l}\text { Augmenting macrophage phagocytosis } \\
\text { and stimulating production of TNF- } \alpha \\
\text { and NO }\end{array}$ & Ni et al. (2010) \\
\hline Heat-processed ginseng & $\begin{array}{l}\text { In vitro, the murine macrophage-like } \\
\text { cell line RAW264.7 }\end{array}$ & $\begin{array}{l}\text { Could enhance the macrophage } \\
\text { activation }\end{array}$ & $\begin{array}{l}\text { Increasing cytokine production and MHC } \\
\text { expression in macrophage cells and } \\
\text { activating MAPKs and NF-kB pathways }\end{array}$ & Shin et al. (2018) \\
\hline
\end{tabular}

Ginsenoside Rg3 In vitro, LLC and melanoma cell lines
B16F10

$\mathrm{M} 1$ and M4

Neutral ginseng

polysaccharides(NGP)

Ginseng polysaccharides

Acidic ginseng ginseng)

Ginseng berry extract

NK cells

Ginsenoside F1

In vitro, human peripheral blood mononuclear cells (PBMCs) derived DCs

In vitro, bone marrow dendritic cells (BMDCs) of C57BL/6 mice

In vivo, NSCLC patients

In vitro, BMDCs of C57BL/6 mice

In vitro, $\mathrm{BMDC}$ of $\mathrm{C} 57 \mathrm{BL} / 6$ mice; in vivo, B16F10-bearing murine model

In vitro, human NK cells isolated from polysaccharides (from red PBMCs; in vivo, lymphoma and melanoma implantation murine model
Could induce DCs maturation

Could stimulate BMDCs maturation, increase spleen DCs proportion and activation; could enhance anti-cancer immune response as an immune adjuvant

Could suppress growth of tumor cells and increase DC uptake function on tumor cells

Could promote DCs maturation, enhance stimulatory efficiency on naive $T$ cells differentiating towards Th1 type and augment the cytotoxicity of CD8+T cells Could promote DCs maturation and increase proliferation of $\mathrm{T}$ cells

Could improve quality of life when treatment with DCs

Could promote the cytotoxicity activity

Could Inhibit tumor growth and metastasis
In vitro and in vivo, murine melanoma cells B16-BL6 and murine tumorbearing model of C57BL/6 mice
Increasing immunogenic cell death of tumor cells; suppressing secretion of IFN- $\gamma$ and inducing secretion of IL-6, TNF- $\alpha$ and TGF- $\beta 1$ of tumor cells. Increasing immune DCs surface expression of CD80, CD83, CD86 and HLA-DR; modulating murine DCs to secrete more IFN- $\gamma$ and less IL-4 cytokines

Increasing expression of CD40, CD80, CD83, CD86 and MHC-II on BMDCs and cytokines IL-12p70 and TNF- $\alpha$ secretion Increasing the level of Th1 cytokines (INF- $\gamma, \mathrm{IL}-2$ ) and the ratio of Th1/Th2 cytokines (INF- $\gamma / \mathrm{IL}-4$, IL-2/IL-5); decreasing the level of Th2 cytokines. Increasing surface markers, MHC II, CD80, CD86, CD83 and CD40 on the $\mathrm{DCs}$, and inducing secretion of higher level of IL-12 and low level of TNF- $\alpha$ Upregulating co-stimulatory molecules and production of pro-inflammatory cytokines of BMDCs and spleen DCs via TLR4 and MyD88 signaling pathways

Increasing the levels of NK cells cytotoxic effector molecules(perforin and granzyme B) and activating signaling downstream (PI3K/Akt) of NK cellactivating receptors (NKG2D and 2B4) and IGF-1 pathway Stimulating splenic NK cells cytotoxic activity against tumor cells
Kwon et al. (2018)

Son et al. (2016)

Takei et al. (2004)

Meng et al. (2013)

Ma et al. (2014)

Wang et al. (2013)

Zhang et al. (2015)

Hasegawa et al. (2002)

(Continued on following page) 
TABLE 2 | (Continued) Effects of ginseng on innate immune cells.

\begin{tabular}{|c|c|c|c|c|}
\hline Components & Cell/animal model & Effects & Main mechanisms & Ref. \\
\hline $\begin{array}{l}\text { Ginseng berry } \\
\text { polysaccharide portion } \\
\text { (GBPP) }\end{array}$ & $\begin{array}{l}\text { In vitro, splenic NK cells of tumor- } \\
\text { bearing BALB/c mice; in vivo, B16- } \\
\text { BL6 melanoma lung cancer } \\
\text { metastasis model of BALB/c mice }\end{array}$ & $\begin{array}{l}\text { Could reduce tumor metastasis } \\
\text { colonies in lung }\end{array}$ & $\begin{array}{l}\text { Promoting NK cell cytotoxicity via the } \\
\text { release of IFN- } \gamma \text { and granzyme B; } \\
\text { enhancing macrophages and cytotoxic T } \\
\text { lymphocytes activity }\end{array}$ & $\begin{array}{l}\text { Lee et al. } \\
\text { (2019a), Lee } \\
\text { et al. (2019b) }\end{array}$ \\
\hline $\begin{array}{l}\text { Ginseng leaves } \\
\text { polysaccharide fraction }\end{array}$ & $\begin{array}{l}\text { In vitro, splenic NK cells of tumor- } \\
\text { bearing BALB/c mice; In vivo, colon } \\
26-\mathrm{M} 3.1 \text { carcinoma cells lung } \\
\text { cancer metastasis model of BALB/c } \\
\text { mice }\end{array}$ & Could inhibit lung metastasis & Activating macrophages and NK cells & Shin et al. (2017) \\
\hline $\begin{array}{l}\text { Ginseng fruits } \\
\text { polysaccharide }\end{array}$ & $\begin{array}{l}\text { In vitro, splenic NK cells of tumor- } \\
\text { bearing C57BL/6 mice and LLC } \\
\text { cells; in vivo, LLC-bearing model }\end{array}$ & $\begin{array}{l}\text { Could Inhibit tumor growth and } \\
\text { metastasis }\end{array}$ & $\begin{array}{l}\text { Enhancing the NK cell-mediated } \\
\text { cytotoxicity }\end{array}$ & $\begin{array}{l}\text { Wang et al. } \\
(2015)\end{array}$ \\
\hline
\end{tabular}

Akt/eNOS signal pathways in vitro (Kim et al., 2012a; Kim et al., 2012b), while also attenuating neo-vessel formation and mobilization of EPCs in vivo, leading to delayed tumor progression and angiogenesis (Kim et al., 2012a). According to Tang et al., ginsenoside $\mathrm{Rg} 3$ appeared to decrease microvessel density levels in colorectal cancer xenografts by downregulating expression of certain angiogenesis-related genes, such as CSF3, FGF2, MMP1, and PGF (Tang et al., 2018). Under TME hypoxic conditions, HIF-1 complex, of which HIF-1a is a key component, could further activate various downstream angiogenic factors in tumor cells, such as VEGF. In other studies, ginsenoside $\mathrm{Rg} 3$ has been shown to inhibit angiogenesis in a variety of tumor models and was shown to inhibit hypoxia-induced VEGF expression in tumor cells (Ge et al., 2014; Li and Qu, 2019; Meng et al., 2019) through regulation of various pathways, such as Akt, ERK, JNK, and STAT3 signaling pathways (Chen et al., 2010; Meng et al., 2019). Another ginsenoside, Rd, was reported to exert anti-angiogenic effects by mitigating VEGF-induced migration, invasion, and capillary formation by human umbilical vascular endothelial cells (HUVECs) and by reducing CD31-positive capillary formation in tumors by inhibiting both VEGF/VEGFR2 signaling cascade pathways Akt/mTOR/p70S6K and HIF-1a expression (Zhang et al., 2017). Meanwhile, ginsenosides Rb1 and Ro have been shown to inhibit HUVEC cell formation into tube-like structures (Lu et al., 2017; Zheng et al., 2019), while the end metabolite of 20(S)-protopanaxadiol-type ginsenosides metabolism, PPD, exerted a pro-apoptotic effect on HUVECs (Wang X. et al., 2019) and ginsenoside Rh2 downregulated tumor cell expression of VEGF and MMPs (Li H. et al., 2018; Zhang et al., 2020).

The tumor vascular network is characterized by dilated, twisted, and disordered immature vessels lacking parietal cells (Figure 1) that exhibit hyperpermeability, poor perfusion, and increased hypoxia (Viallard and Larrivée, 2017). Recent data have demonstrated that some ginsenosides, such as F1 and Rh1, act to reduce vascular leakage induced by VEGF by suppressing mRNA transcription and protein expression of NR4A1 (Kang et al., 2019), leading to vascular normalization that prevents tumor cell extravasation and metastasis.

\section{GINSENG MAY REGULATE THE TUMOR IMMUNOSUPPRESSIVE MICROENVIRONMENT}

An important component of the TME, infiltrating immune cells, can be classified as tumor-suppressors and tumor-promotors based on functions of these tumor-associated cells (Lei et al., 2020). In general, although immune cells within the body are capable of recognizing and killing tumor cells, anti-tumor immune responses in the TME are suppressed due to direct or indirect tumor interference with, and/or inhibition of, functions of tumor-antagonizing immune cells acting via many mechanisms. Ultimately, dysfunctional immunoregulation within the TME promotes proliferation and differentiation of tumor-promoting immune cells that eventually lead to abnormal immunosurveillance and tumor cell immune escape ( $\mathrm{Li} \mathrm{W}$. et al., 2020; Lei et al., 2020; Liskova et al., 2020). Several active components of ginseng may exert anti-tumor effects by interfering with the differentiation and maturation of tumorpromoting immune cells, leading to reversal of the inhibitory phenotype of tumor-antagonizing immune cells and restoration of anti-tumor functions of innate (Table 2) and acquired immune cells.

\section{Ginseng Enhancement of the Innate Immune Response Macrophages}

Macrophages exhibit developmental plasticity and can differentiate into pro-inflammatory (M1) and antiinflammatory (M2) phenotypes according to different pathological environments (Wang Y. et al., 2019). Available studies indicate that tumor-associated macrophages (TAMs) derived from circulating monocytes and myeloid-derived suppressor cells (MDSCs) mainly possess characteristics and phenotypes of pro-tumorigenic M2-polarized macrophages that promote tumor angiogenesis, enhance tumor metastasis, and inhibit anti-tumor T cell immunity (Kim and Bae, 2016). Thus, strategies that Increase the M1/M2 ratio or inhibit effects of M2-polarized cells are promising anti-tumor therapeutic approaches that work by targeting the TME. 


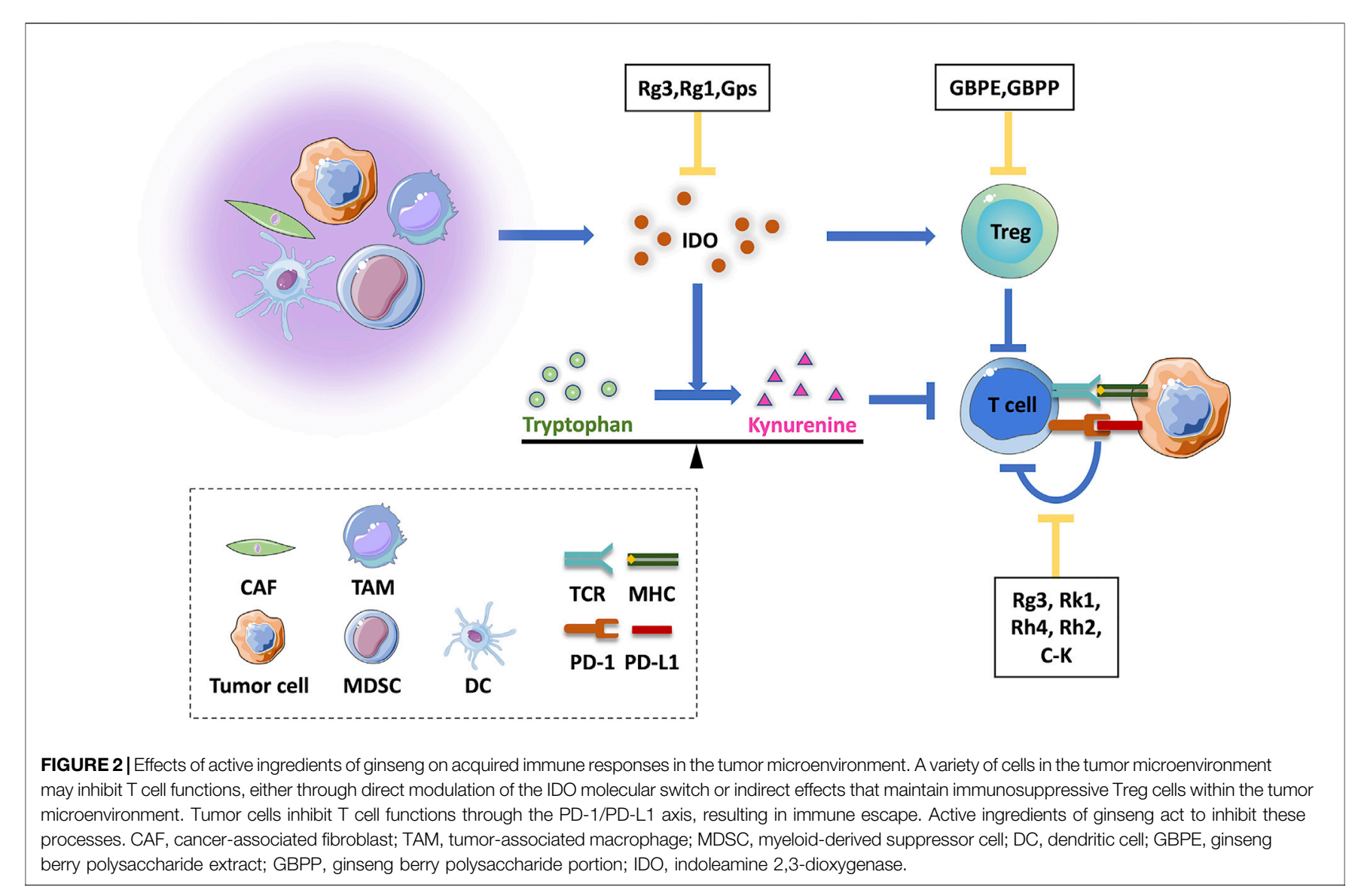

Recent studies have shown that ginsenosides may help to regulate the two subpopulations of TAMs. One such study declared that ginsenoside $\mathrm{Rg} 3$ treatment led to an improved anti-tumor effect based on the re-education and conversion of TAMs from an M2 phenotype to an M1 phenotype when Rg3 was delivered to cells within liposomes that were also loaded with paclitaxel (Rg3-PTX-LPs) (Zhu et al., 2021). Another ginsenoside, Rh2, has also been shown to alter the TME by inducing conversion of TAMs from an M2 to an M1 phenotype that, in turn, prevented tumor cell migration and secretion of tumor angiogenetic factors (Li H. et al., 2018). Meanwhile, ginsenoside Rp1 was shown to inhibit murine macrophage radiation-induced DNA damage. After colon cancer cells were exposed to conditioned medium from radiation-potentiated macrophages, it was found that culture supernatant of Rp1-treated macrophages inhibited growth and metastasis of tumor cells and prolonged survival of tumorbearing mice in vivo (Baik et al., 2020). In yet another study, treatment of RAW264.7 cells, a macrophage-derived cell line, with heat-processed ginseng (HPG) containing Rg3, Rk1, and Rg5 that enhanced macrophage cell functions that included cytokines production, MHC class I and II expression, and NF$\kappa B$ transcriptional activity (Shin et al., 2018).

Another component of ginseng, polysaccharides, are recognized as immunomodulators (Zeng et al., 2019; Qi et al., 2021). It has shown that the addition of red ginseng acidic polysaccharide (RGAP) or IFN- $\gamma$ alone to murine melanoma B16 cells exerted no cytotoxic effect, while each weakly activated macrophages. It is worth noting that RGAP administered with IFN- $\gamma$ markedly stimulated macrophages to secrete proinflammatory cytokines resembling those secreted by M1 macrophages (e.g., IL-1, IL-6, TNF- $\alpha$ ) due to triggering of the NF- $\kappa B$ pathway, leading to dramatic enhancement of MHCunrestricted macrophage-mediated cytotoxicity (Choi et al., 2008). The non-selective cytotoxicity of most chemotherapeutic drugs, while achieving desired anti-tumor effects, can lead to collateral damage of immune cells, prompting researchers to investigate ginseng effects for alleviating immune cell damage. In one such study, ginseng neutral polysaccharides were shown to reverse 5-fluorouracilinduced splenic weight decreases and inhibition of macrophage phagocytosis to restore macrophage production of NO and TNF$\alpha$ (Ni et al., 2010). Therefore, ginseng active ingredients appear to have the potential to induce macrophages to transform into proinflammatory cells with heightened ability to kill tumor cells, while also potentially alleviating macrophage damage caused by effects of radiotherapy and chemotherapy.

\section{Dendritic Cells}

Dendritic cells (DCs), which function as professional antigen presenting cells (APCs), play pivotal roles in initiating innate and adaptive immunity, with the latter role associated with DCs 
TABLE 3 | Effects of ginseng on cancer stem cells.

\begin{tabular}{|c|c|c|c|c|}
\hline Components & Cell/animal model & Effects & Main mechanisms & Ref. \\
\hline $\begin{array}{l}\text { Fermented red ginseng with } \\
\text { L. rhamnosus KCTC } 5033\end{array}$ & $\begin{array}{l}\text { In vitro, mimicking breast cancer } \\
\text { stem cells MCF-7 }\end{array}$ & $\begin{array}{l}\text { Could reduce the viability of reprogrammed } \\
\text { MCF- } 7 \text { cancer stem-like cells }\end{array}$ & Not clear & $\begin{array}{l}\text { Oh et al. } \\
(2015)\end{array}$ \\
\hline Ginsenoside Rg3 & $\begin{array}{l}\text { In vitro, colorectal cancer } \\
\text { cells(CRC) LoVo. In vivo, CRC } \\
\text { cells LoVo orthotopic xenografts }\end{array}$ & $\begin{array}{l}\text { Could repress the growth and migration } \mathrm{CRC} \\
\text { cells and strengthen the cytotoxicity of } 5-\mathrm{Fu} \\
\text { and oxaliplatin }\end{array}$ & $\begin{array}{l}\text { Partly depend on decreasing proportion of } \\
\text { stem cells expressing CD24+/CD44+/ } \\
\text { EpCAM+ and attenuate the stemness of } \\
\text { CRC cells }\end{array}$ & $\begin{array}{l}\text { Tang et al. } \\
\text { (2018) }\end{array}$ \\
\hline Ginsenoside Rg3 & $\begin{array}{l}\text { In vitro, stem-like NSCLC cells } \\
\text { H1975, Osimertinib-resistant } \\
\text { H1975 cells(H1975-OR) }\end{array}$ & $\begin{array}{l}\text { Could decrease spheroid formation ability, } \\
\text { expression of stemness-related markers, } \\
\text { ALDH activity, and attenuate the Osimertinib } \\
\text { resistance of NSCLC cells }\end{array}$ & Activating Hippo signaling & $\begin{array}{l}\text { Tan et al. } \\
(2020)\end{array}$ \\
\hline Ginsenoside Rg3 & $\begin{array}{l}\text { In vitro and in vivo, stem-like } \\
\text { NSCLC cells H1299 and A549 }\end{array}$ & $\begin{array}{l}\text { Could inhibit spheroid formation ability, } \\
\text { expression of stemness-related markers, } \\
\text { sensitize hypoxic NSCLC cells to cisplatin }\end{array}$ & Inhibiting NF-kB signaling pathway & $\begin{array}{l}\text { Wang } \\
\text { et al. } \\
\text { (2018) }\end{array}$ \\
\hline 20(R)-Ginsenoside Rg3 & $\begin{array}{l}\text { In vitro, CRC cells HT29 and } \\
\text { SW620 }\end{array}$ & $\begin{array}{l}\text { Could downregulate the levels of stemness } \\
\text { genes and EMT markers }\end{array}$ & Inhibiting EGFR/SNAIL signaling & $\begin{array}{l}\text { Phi et al. } \\
\text { (2019a) }\end{array}$ \\
\hline $\begin{array}{l}\text { Standardized Korean Red } \\
\text { Ginseng extract (RGE), } \\
\text { ginsenoside Rg3 }\end{array}$ & $\begin{array}{l}\text { In vitro, stem-like breast cancer } \\
\text { cells MCF-7 and MDA-MB-231 }\end{array}$ & $\begin{array}{l}\text { Could decrease the viability, number and the } \\
\text { size of mammospheres, proportion of } \\
\text { CD } 44^{\text {high }} / C D 24^{\text {low }} \text { CSCs and ALDH positive } \\
\text { cells, and reduce the expression of self- } \\
\text { renewal signaling molecules }\end{array}$ & $\begin{array}{l}\text { Partially dependent on the PI3K/Akt } \\
\text { pathway }\end{array}$ & $\begin{array}{l}\text { Oh et al. } \\
(2019)\end{array}$ \\
\hline $\begin{array}{l}\text { Fermented ginseng extract } \\
\text { BST204 }\end{array}$ & $\begin{array}{l}\text { In vitro, embryonic carcinoma } \\
\text { cells NCCIT }\end{array}$ & $\begin{array}{l}\text { Could downregulate the levels of stemness } \\
\text { and stem-related transcription factors genes, } \\
\text { and inhibit CSCs tumorigenesis }\end{array}$ & Target CD133 & $\begin{array}{l}\text { Park et al. } \\
(2020)\end{array}$ \\
\hline Ginsenoside Rd & $\begin{array}{l}\text { In vitro, CSC-like CRC cells HT29 } \\
\text { and SW620 }\end{array}$ & $\begin{array}{l}\text { Could suppress the growth of CSCs, and } \\
\text { downregulate expression levels of CSC } \\
\text { markers. }\end{array}$ & Inhibiting EGFR/Akt signaling & $\begin{array}{l}\text { Phi et al. } \\
\text { (2019b) }\end{array}$ \\
\hline Ginsenoside Rg5 and Rk1 & $\begin{array}{l}\text { In vitro, human NSCLC cells } \\
\text { A549 }\end{array}$ & $\begin{array}{l}\text { Could inhibit tumorsphere formation ability, } \\
\text { suppressed the stem cell-like properties }\end{array}$ & $\begin{array}{l}\text { Suppressing Smad2/3, NF-kB, ERK, p38 } \\
\text { MAPK, and JNK pathways }\end{array}$ & $\begin{array}{l}\text { Kim et al. } \\
(2021)\end{array}$ \\
\hline
\end{tabular}

presentation of exogenous tumor-associated antigens on MHC I molecules to naive $\mathrm{CD}^{+} \mathrm{T}$ cells to initiate anti-tumor immunity. However, the activity of DCs to induce anti-tumor responses is suppressed by TME dampening of DC maturation, differentiation, or cell migration, with numerous TME effector molecules (e.g., IL-6, IL-10, VEGF, TGF- $\beta$, CSF-1) involved in suppression of DC activities (Fu and Jiang, 2018; Bandola-Simon and Roche, 2019; Del Prete et al., 2020). Defective DCs that cannot properly perform their sentinel function have been detected in various cancers, such as breast cancer (Gervais et al., 2005), colorectal cancer (Legitimo et al., 2014), and ovarian cancer (Jiang et al., 2018). Increased immunogenic tumor cell death may contribute to maturation and tumor antigen-presentation activity of DCs resulting from release of damage-associated molecular patterns (DAMPs) molecules from tumor cells, such as chaperone protein calreticulin (CRT), high mobility group box-1 protein (HMGB1), and heat shock proteins (HSPs). Keum-joo Son et al. (Son et al., 2016) reported that ginsenoside Rg3 was able to act as an immunomodulator to increase DC uptake of tumor cells by inducing immunogenic tumor cell death and enhancing immunogenicity of cancer cells. Furthermore, ginsenoside $\mathrm{Rg} 3$ could stimulate tumor cells to produce IFN- $\gamma$, an anti-tumor cytokine secreted by T cells, while suppressing tumor cell secretion of TGF- $\beta$ and IL-6 (Son et al., 2016). In other work, Takei et al. (Takei et al., 2004) demonstrated that M1 and M4, end products of steroidal ginseng saponins metabolized within the digestive tract, exerted immunomodulatory effects on DCs by inducing DCs maturation, as reflected by upregulation of DC surface expression of maturation marker molecules CD80, CD83, CD86, and HLADR. In turn, mature DCs enhanced the polarization of Th1 cells that increased anti-tumor immunity. In addition, ginseng polysaccharides have been shown to stimulate maturation of murine bone marrow dendritic cells (BMDCs), as revealed by changes in cell morphology, upregulation of membrane phenotypic markers (e.g., CD40, CD80, CD83, CD86, MHC II), and increased pro-inflammatory cytokine production (Meng et al., 2013; Wang et al., 2013).

\section{Natural Killer Cells}

As for DCs, natural killer (NK) cells in the TME are also dysfunctional (Round and Mazmanian, 2010). Results of studies based on mouse models of lymphoma clearance and metastatic melanoma demonstrated that ginsenoside F1 could enhance NK cell cytotoxicity against diverse types of cancer cells, while also improving NK cell cancer surveillance ability by upregulating NK cell secretion of cytotoxic mediators and NK activation signal molecules (Kwon et al., 2018). Meanwhile, oral administration of 20(S)-protopanaxatriol (M4), an intestinal bacterial metabolite of ginsenosides, led to complete absorption of M4 by the small intestine followed by transfer of most of the substance to the mesenteric lymphatics, where it was esterified to form EM4 that then spread to other organs in the body. Notably, EM4 was shown to stimulate tumor lysis mediated by NK cells in a B16-BL6 melanoma metastasis mouse model (Hasegawa et al., 2002). In another study, pectin polysaccharide 
TABLE 4 | Structure and extraction method of polysaccharide from ginseng.

\begin{tabular}{|c|c|c|c|c|}
\hline Polysaccharide & Extraction and separation method & $\begin{array}{l}\text { Composition sugar ratio } \\
\text { (Mass percentage or molar ratio) }\end{array}$ & $\begin{array}{l}\text { Molecular } \\
\text { weight }\end{array}$ & Ref. \\
\hline $\begin{array}{l}\text { Red ginseng acidic } \\
\text { polysaccharide (RGAP) }\end{array}$ & $\begin{array}{l}\text { Distilled water percolation, precipitation by } 85 \% \text { ethanol, } \\
\text { purification by dialysis }(15 \mathrm{kDa})\end{array}$ & GlcA: Glc: GalA = 51.8: 26.1: 5.1 & $>15 \mathrm{kDa}$ & $\begin{array}{l}\text { Choi et al. } \\
(2008)\end{array}$ \\
\hline $\begin{array}{l}\text { Ginseng neutral } \\
\text { polysaccharide fraction }\end{array}$ & $\begin{array}{l}\text { Hot water exaction, precipitation by } 95 \% \text { ethanol, } \\
\text { purification by Sevage and DEAE -Cellulose }\end{array}$ & Glc: Gal: Ara = 95.3\%: 3.3\%: 1.3\% & - & Ni et al. (2010) \\
\hline $\begin{array}{l}\text { Neutral ginseng } \\
\text { polysaccharides (NGP) }\end{array}$ & NGP bought from Pude Pharmaceutical Company & Main ingredients is $\alpha-(1 \rightarrow 6)-D-G l u c a n$ & $504 \mathrm{Da}$ & $\begin{array}{l}\text { Meng et al. } \\
\text { (2013) }\end{array}$ \\
\hline Ginseng polysaccharides & $\begin{array}{l}\text { GPS injection was bought from Shanxi Pude } \\
\text { pharmaceutical Co., Ltd., Shanxi, China }\end{array}$ & - & - & $\begin{array}{l}\text { Ma et al. } \\
(2014)\end{array}$ \\
\hline $\begin{array}{l}\text { Acidic ginseng } \\
\text { polysaccharides (AGP) }\end{array}$ & $\begin{array}{l}\text { AGP (>99\% purity, } 3 \mathrm{mg} / \mathrm{ml} \text { ) was bought from Pude } \\
\text { pharmaceutical company, Shanxi, China }\end{array}$ & $\begin{array}{l}\text { Sugar of composition are GalA, Glc, Ara, Xyl } \\
\text { and Rha }\end{array}$ & $66 \mathrm{kDa}$ & $\begin{array}{l}\text { Wang et al. } \\
(2013)\end{array}$ \\
\hline $\begin{array}{l}\text { Ginseng berry } \\
\text { polysaccharide portion } \\
\text { (GBPP) }\end{array}$ & $\begin{array}{l}\text { Hot water exaction, precipitation by } 95 \% \text { ethanol, } \\
\text { purification by dialysis }(20 \mathrm{kDa})\end{array}$ & $\begin{array}{l}\text { Rha: Fuc: Ara: Xyl: Man: GalA: Glc = 8.4: } \\
\text { 19.5: 2.2: } 1.5: 39.8: 5.4\end{array}$ & $>20 \mathrm{kDa}$ & $\begin{array}{l}\text { Lee et al. } \\
\text { (2019a) }\end{array}$ \\
\hline GBPP-I & $\begin{array}{l}\text { Hot water exaction, precipitation by } 90 \% \text { ethanol, } \\
\text { purification by dialysis }(20 \mathrm{kDa}) \text { and } \mathrm{G}-75 \text { gel permeation } \\
\text { column }\end{array}$ & $\begin{array}{l}\text { Glc: GalA: Gal: Ara: Rha = 5.4: 10.4: 46.9: } \\
\text { 27.5: } 6.7\end{array}$ & $76 \mathrm{kDa}$ & $\begin{array}{l}\text { Lee et al. } \\
\text { (2019b) }\end{array}$ \\
\hline $\begin{array}{l}\text { Ginseng leaves } \\
\text { polysaccharide fraction }\end{array}$ & $\begin{array}{l}\text { Hot water exaction, purification by Diaion HP-20 column } \\
\text { and Diaion PA312 column, precipitation by } 95 \% \text { ethanol } \\
\text { and dialysis }(1000 \mathrm{Da})\end{array}$ & $\begin{array}{l}\text { Rha: Fuc: Ara: Gal: GalA: GlcA: Man: Xyl= } \\
\text { 10.2: 3.1: 14.4: 11.8: 37.3: 2.5: 0.7: } 0.9\end{array}$ & $10.2 \mathrm{kDa}$ & $\begin{array}{l}\text { Shin et al. } \\
(2017)\end{array}$ \\
\hline $\begin{array}{l}\text { Ginseng fruits } \\
\text { polysaccharide }\end{array}$ & $\begin{array}{l}\text { Hot water exaction, precipitation by } 95 \% \text { ethanol, } \\
\text { purification by Sevage, DEAE-cellulose- } 52 \text { and Sepharose } \\
\text { CL-6B column }\end{array}$ & Gal: Glc: Rha: Ara = 6.1: 2.0: 1.1: 3.2 & $140 \mathrm{KDa}$ & $\begin{array}{l}\text { Wang et al. } \\
\text { (2015) }\end{array}$ \\
\hline
\end{tabular}

fraction (GS-P) purified from ginseng leaves was shown to inhibit proliferation and metastasis of colon cancer cells; these effects were not based on direct cytotoxicity, but were instead based on stimulation of macrophage and NK cell activities (Shin et al., 2017). A similar conclusion was obtained in a study of ginseng berry polysaccharide portion (GBPP), which stimulated macrophages to secrete anti-tumorigenic cytokines (e.g., IL-6, IL-12, TNF- $\alpha$ ) while also promoting NK cells to release IFN- $\gamma$ and granzyme B that inhibited tumor cells activities (Lee et al., 2019a; Lee et al., 2019b). Moreover, another study of polysaccharides purified from ginseng fruits demonstrated that ginseng polysaccharides could significantly enhance NK cellmediated cytotoxicity in tumor-bearing mice (Wang et al., 2015). Taken together, these results indicate that active components of ginseng exert anti-tumor effects by correcting impaired NK cell killing of tumor cells that, in turn, effectively inhibit tumor metastasis.

\section{Ginseng Enhancement of the Adaptive Immune Response \\ Adaptive Immune Cells}

In addition to ginseng effects for reversing tumor inhibition of innate immune cell activities, ginseng has also been shown to reverse tumor-inhibited adaptive immune cell activities. For example, regulatory $\mathrm{T}$ cells (Tregs) (identified based on the presence of foxp $3+\mathrm{CD} 25+\mathrm{CD} 4^{+}$cell surface markers) actively engage in maintenance of immunological self-tolerance, as well as in inhibition of immune responses within the TME (Dong et al., 2020). In fact, Tregs have been found to infiltrate the tumor site, where they suppress the anti-tumor response, with suppression reversed by depletion of Tregs. Using chronic intestinal inflammation as a model system of colorectal cancer (due to the close clinical relationship between the two diseases), ginseng berry polysaccharide extract (GBPE) and GBPP obtained from Asian ginseng berries were shown to exert anti-inflammatory effects in vitro that were linked to inhibition of secretion of IL-8, a proinflammatory factor closely tied to intestinal inflammation. Moreover, by inhibiting $\mathrm{T}$ cell differentiation into Th1 cells (which promote intestinal inflammation) and Treg cells (which weaken the body's anti-tumor immunity), intestinal inflammation may be reduced and anti-tumor effects of chemotherapy drugs synergistically enhanced so as to effectively inhibit proliferation of colorectal cancer cells (Wang et al., 2020).

Indoleamine-2,3-dioxygenase (IDO) is an intracellular hemecontaining enzyme within the kynurenine (Kyn) pathway that catabolizes tryptophan (Trp). Due to its role in tumor immune escape mechanisms, IDO expression has been found in tumor cells, DC cells, endothelial cells and even stromal cells in the TME, where it inhibits CTL infiltration and cell functions while inducing Treg recruitment (Uyttenhove et al., 2003; Löb et al., 2009; Sharma et al., 2010; Munn and Mellor, 2016). Using the ratio of Kyn to Trp as a marker of IDO enzymatic activity, results of a study based on a mouse model of inflammation indicated that ginseng total saponins could decrease the plasma Kyn/Trp ratio (Kang et al., 2011). Since then, researchers have also found that ginsenoside Rg3 treatment similarly reduced IDO activity in the periphery and brain (Kang et al., 2017). In an in vivo liver fibrosis mouse model and in in vitro experiments, ginsenoside Rg1 was also observed to inhibit IDO1 protein expression and enhance DCs activities and $\mathrm{T}$ cell infiltration, thereby enhancing the immune response (Mo et al., 2021). Recent studies have shown that ginseng polysaccharides enhanced the anti-tumor 


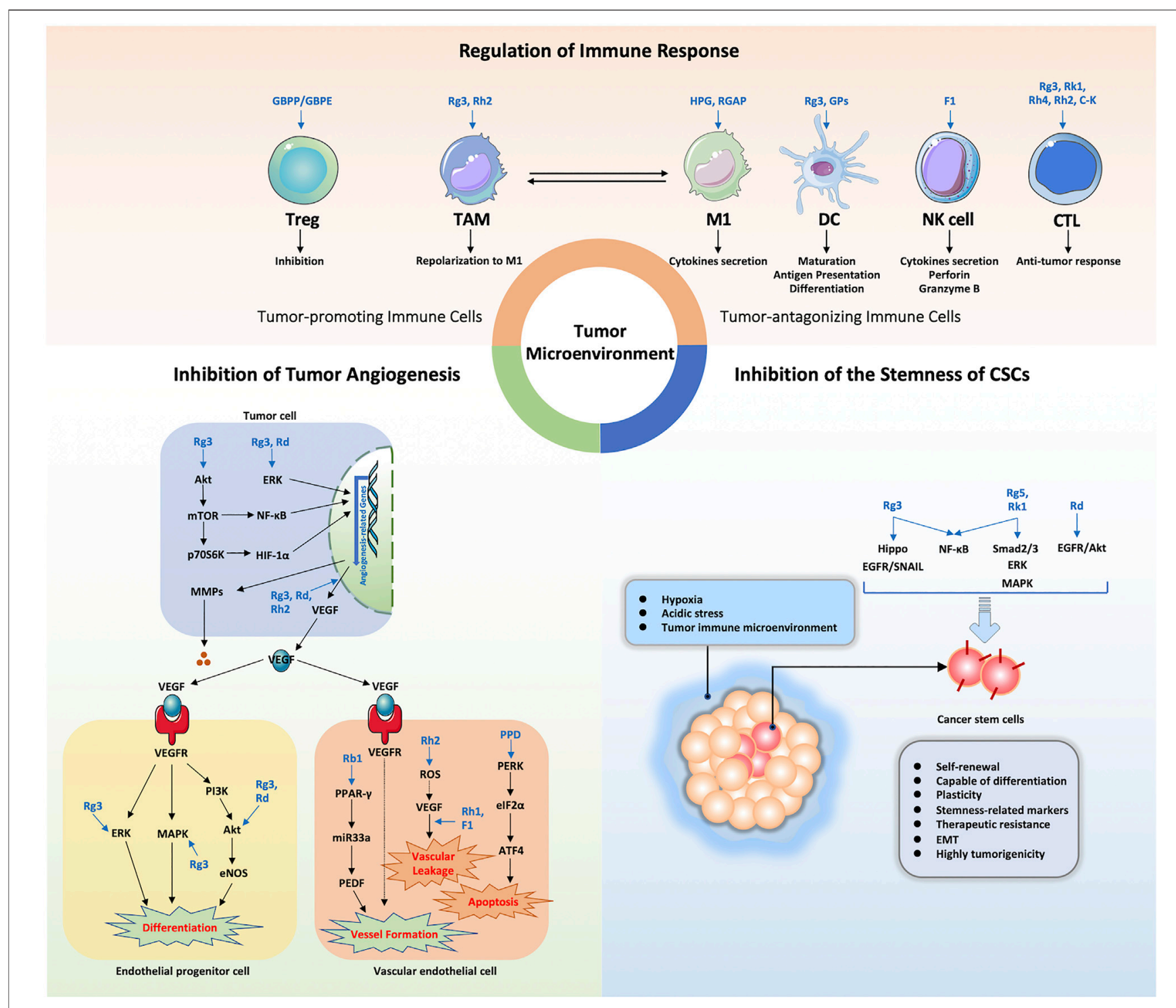

FIGURE 3 / Summary of the functional effects and mechanisms underlying TME regulation by ginseng active ingredients via multiple targets. HPG, heat-processed ginseng; RGAP, red ginseng acidic polysaccharide; GPs, ginseng polysaccharides; NK cell, natural killer cell; CTL, cytotoxic T lymphocyte.

response triggered by anti-PD- $1 \mathrm{mAb}$ by increasing $\mathrm{CD} 8^{+} \mathrm{T}$ cell function and decreasing Treg inhibition. These effects may have been due to effects of ginseng polysaccharides on tryptophan metabolism that acted to reshape the gut microbiota that resulted in significantly increased production of L-tryptophan and decreased production of L-kynurenine and IDO expression in tumor cells (Huang et al., 2021). In conclusion, ginsenosides and ginseng polysaccharides appear to enhance the adaptive immune response against tumor cells, warranting further study (Figure 2).

\section{Enhancement of Immunogenicity of Tumor Cells}

Immunogenicity of tumor cells is key to inducing an anti-tumor immune response. Generally, cancer cells could evade anti-tumor immunity by adopting active immunogenicity reduction strategies, including reduced expression of tumor antigens, diminished MHC-I expression for reduced antigenic recognition by $\mathrm{T}$ cells, and aberrant expression of immune checkpoint proteins, such as programmed death ligand-1 (PDL1), which inhibits existing host anti-tumor immunity (Kim and Seo, 2018; Looi et al., 2019; Tang et al., 2014). Furthermore, PDL1 expression can be up-regulated in tumor cells that are resistant to chemotherapeutic agents (Shen et al., 2019; Wu et al., 2021), including tumor-targeting drugs such as EGFR-TKI (Peng et al., 2019), thus promoting immune escape of tumor cells. Although inhibitors targeting immune checkpoints have been developed and have become a focal point of clinical cancer therapy, current low treatment response rates, high incidence of side-effects, and acquired resistance are still unavoidable challenges. Nevertheless, effective reduction of PD-L1 expression in tumor cells appears to anti-tumor immunity and reduce tumor drug resistance, as 
shown in a study whereby PD-L1 protein was overexpressed in cisplatin-resistant human non-small cell lung cancer (NSCLC) cell line A549/DDP. In these experiments, ginsenoside Rg3 was shown to significantly block PD-L1 overexpression in A549/DDP cells, an effect that was associated with inhibition of activation of Akt and NK- $\kappa \mathrm{B}$ pathways. Additional in vitro experiments confirmed that when A549/DDP cells were co-cultured with $\mathrm{CD}^{+} \mathrm{T}$ cells, Rg3 could target chemotherapy-induced PD-L1 and enhance the immunocytotoxicity of $\mathrm{CD}^{+} \mathrm{T}$ cells (Jiang et al., 2017). Moreover, when loaded into carbon nanotubes (CNT) (Luo et al., 2021), Rg3 inhibited expression of PD-L1 by triplenegative breast cancer cells. Remarkably, CNTs-loaded with Rg3 could attenuate PD-1 expression in activated T cells and reduce PD-1/PD-L1 axis activity in vitro. Meanwhile, other ginsenosides such as Rk1 (Hu et al., 2020), Rh4 (Deng et al., 2020), and Rh2 (Chen Y. et al., 2020) have also been reported to downregulate PD-L1 expression in tumor cells (Figure 2). In addition, ginsenosides have been shown to exert a competitive inhibitory effect on the PD-1/PD-L1 interaction. Specifically, eight ginsenosides (Rd, F2, Rg3, C-K, Rh2, PPD, Rg1, Rh1) were confirmed to block the PD-1/PD-L1 binding interaction, whereby a blocking ability of $35 \%$ was observed at the maximum ginsenoside concentration $(1 \mu \mathrm{M})$, with Rg3 and C-K exerting the most significant effects. Further analyses based on molecular docking and pharmacophore analysis suggested that $\mathrm{Rg} 3$ and $\mathrm{C}-\mathrm{K}$ may achieve an immune checkpoint blockade through multiple hydrophobic and hydrogen bonds with PD-1/PD-L1 molecules (Yim et al., 2020).

\section{GINSENG COULD INHIBIT STEMNESS OF CANCER STEM CELLS}

In recent decades, rare stem-like cells known as cancer stem cells (CSCs) have been detected in tumors. CSCs possess characteristics of self-renewal, strong xenograft tumorigenesis properties, and resistance to conventional therapy (radiation and chemotherapy) and resemble bone marrow hematopoietic stem cells. In general, CSCs are dormant except during long-term tumor growth, where they can become activated to engage in self-renewal and differentiation to generate heterogeneous tumor cells with epithelial-mesenchymal transition (EMT) characteristics (López de Andrés et al., 2020). CSCs have been identified using various identification methods, including in vivo limiting-dilution tumorigenicity assays in immunodeficient mice, in vitro tumorsphere formation assays, and assays to detect particular surface markers (Walcher et al., 2020). In multiple types of solid tumors, such as breast cancer (Bai et al., 2018), lung cancer (Heng et al., 2019), brain cancer (Singh et al., 2003), and colon cancer (Gupta et al., 2019), CSCs have been identified and found to play crucial roles in tumor proliferation, metastasis, relapse, and chemotherapy/radiation resistance resulting in failures of anti-cancer therapies. Maintenance of CSCs is dependent on TME characteristics such that the acidic and hypoxic environment of the TME may support the establishment and maintenance of CSCs stemness properties, while initiating and regulating stem cell-like programs through various developmental signaling pathways. Such pathways are crucial for maintenance of stem and progenitor cell homeostasis and functions and include Norch, WNT, Hedgehog, and Hippo pathways (Meurette and Mehlen, 2018; Clara et al., 2020). Recent studies have found that endothelial cells/pericytes within some tumor vessels may be generated via differentiation from CSCs (Krishna Priya et al., 2016), thus highlighting CSCs as a novel promising target for use in regulating the TME.

Ginseng has been reported to decrease the size of the CSCs population (Table 3). A Korean research team fermented red ginseng with Lactobacillus rhamnosus KCTC 5033 (f-RGE) to increase $\mathrm{Rg} 3$ content level and found that $\mathrm{f}$-RGE had the potential to inhibit differentiation of breast cancer stem cell-like cells in the presence of carcinogens (Oh et al., 2015). It was further demonstrated that in vitro, $\mathrm{Rg} 3$ treatment could reduce the size of the population of CD24+/CD44+/EpCAM+ colon cancer stem cells and inhibit their clone-forming ability, with similar results obtained from an in vivo orthotopic xenograft model study (Tang et al., 2018) and a breast cancer study (Oh et al., 2019). In addition, ginseng had the potential to modulate the CSC phenotype. For example, BST204, a fermented ginseng extract containing high quantities of $\mathrm{Rh} 2$ and $\mathrm{Rg} 3$, strongly suppressed cancer stemness of embryonic carcinoma cells by downregulating stemness markers and transcription factors at both transcriptional and protein expression levels (Park et al., 2020). Meanwhile, ginsenoside Rg3 was also shown to decrease tumor CSC sphere-forming capacity that led to deregulated expression of stemness-related markers and attenuated CSC tumorigenic activities in several types of cancer (Wang et al., 2018; Phi et al., 2019a; Oh et al., 2019; Tan et al., 2020). Moreover, it has been reported that ginsenoside Rd may downregulate levels of genes related to stemness and EMT by binding to epidermal growth factor receptor (EGFR) (Phi et al., 2019b). Additionally, ginsenosides $\mathrm{Rk} 1$ and $\mathrm{Rg} 5$ have also been reported to suppress expression levels of lung CSC surface markers CD44 and CD133 and transcriptional regulators Nanog, Oct4, and Sox2 (Kim et al., 2021). Furthermore, the inhibitory effect of ginsenosides on stemness of CSCs has been shown to increase cell sensitivity to chemotherapeutic treatments while also reducing resistance to chemotherapy (Tang et al., 2018; Wang et al., 2018; Tan et al., 2020). At present, mechanisms whereby ginsenosides regulate CSCs are still unclear, while results regarding effects of ginsenosides on CSCs in the TME and effects of other ginseng active ingredients on CSCs await future verification. However, from the body of accumulated data, it is apparent that ginseng holds great promise as a drug for targeting CSCs.

\section{CONCLUSION}

The TME, a complex ecological system composed of a variety of cells and stroma, is a hotbed of tumor development. Tumor cell interactions with the TME lead to greater tumor cell aggressiveness and resistance to conventional drugs and radiation. Therefore, anti-tumor therapies should both 
eliminate tumor cells and interfere with communication between tumor cells and the TME.

Due to the fact that targeting of the TME is a promising anticancer strategy, agents that target TME inputs hold great promise as future anti-cancer drug treatments. Such agents in current use include monoclonal antibodies against three key targets: immune checkpoints PD-1 and CTLA-4, which enhance tumor-killing $\mathrm{T}$ cell immune functions; pro-angiogenic factor VEGF; and integrin adhesion molecules that mediate interactions between tumor cells and the TME matrix. However, anti-cancer drugs inevitably have side effects and development of new anti-cancer compounds and antibodies is extremely expensive, although screening of databases containing information for a huge array of natural compounds is a relatively inexpensive and effective approach for identifying potential anti-cancer drugs.

Ginseng is a versatile natural herbal medicine that has been shown to exert good anti-inflammatory, antioxidant, and antiaging therapeutic effects. In fact, ginsenosides, which are mainly found in ginseng root, are considered to be the most important biologically active components of ginseng preparations. So far, more than 180 types of ginsenosides have been isolated from ginseng (Xu et al., 2021). In addition, another active ingredient of ginseng, polysaccharides (the structure and extraction method of polysaccharides are listed in Table 4), also possess beneficial activities for modulating immune regulatory functions. Inhibitory effects of some ginsenoside monomers and ginseng polysaccharides on cancer cell activities have been studied, with regulatory effects of ginseng on TME under increasing scrutiny. In this review, ginseng effects on tumor angiogenesis, the tumor immunosuppressive microenvironment, and tumor stem cells are summarized.

The gut microbiota maintains a symbiotic relationship with intestinal mucosa, the largest immune organ of the human body. The importance of this symbiotic interaction to host well-being is based on its ability to shape the host immune system by regulating local and systemic immune responses. For example, gut microbiota and metabolites may activate DCs in the local intestine, thereby activating the transformation of primitive $\mathrm{T}$ cells into effector $\mathrm{T}$ cells in mesenteric lymph nodes, with special importance for development of Treg and Th17 cells (Round and Mazmanian, 2010; Cheng et al., 2019). Alternatively, metabolites of the gut microbiota could also enter the blood circulation, thus affecting the immune function of the entire body (Rooks and Garrett, 2016; Ohno, 2020). A large body of experimental evidence suggests that gut microbes influence tumorigenesis and functions of immune cells in the TME by regulating production of cytokines (De Almeida et al., 2019; Untersmayr et al., 2019; Li Q. et al., 2020; Chen et al., 2021). In addition, gut microbes are closely associated with the efficacy and toxicity of anti-tumor immunotherapies, such as adoptive cell transfer therapy (Viaud et al., 2013; Nelson et al., 2015; Uribe-Herranz et al., 2018) and immune checkpoint inhibitors (Vétizou et al., 2015; Gopalakrishnan et al., 2018; Routy et al., 2018; Elkrief et al., 2019). Therefore, the gut microbiota not only serves as a new observational index of tumor immunotherapy, but also holds promise as an antitumor therapeutic target. In accordance with these concepts, previous studies indicated that the efficacy of oral ginseng was related to gut microbiome-mediated metabolic transformation involving two types of ginsenoside biotransformation: conversion of protopanaxadiol-type ginsenosides to form compound $\mathrm{K}$ and ginsenoside $\mathrm{Rh} 2$; conversion of protopanaxatriol-type ginsenosides to form ginsenosides $\mathrm{Rh} 1$ and protopanaxatriol (Kim, 2018). Interestingly, ginsenosides and ginseng polysaccharides have also been used to regulate the structure of the gut microbiome for treating a variety of diseases, such as obesity (Song et al., 2014; Lee et al., 2021), diabetes (Li J. et al., 2018; Xu et al., 2020), colitis (Wang et al., 2016; Chen L. et al., 2020), and antibiotic-related diarrhea (Qu et al., 2021). With regard to cancer, a recent study showed that oral ginseng polysaccharides combined with anti-PD-1-mAb could improve therapeutic sensitivity of anti-PD-1-mAb in patients with NSCLC. This effect may have been related to ginseng polysaccharides-induced remodeling of gut microbiota structure in chemotherapeutic non-responders that led to increased abundance of metabolites, such as short-chain fatty acids (SCFAs), while also down-regulating IDO activity (Huang et al., 2021). Thus, the immunosuppressive TME associated with NSCLC was altered, leading to heightened immunotherapeutic sensitivity induced by ginseng polysaccharides administration. Consequently, we hypothesized that the regulatory effects of active ingredients of ginseng on anti-tumor immunity and on the tumor immunosuppressive microenvironment may be partly related to the gut microbiome, although we have found only a few published reports describing such an association. Nevertheless, interrelationships between the regulation of gut microbiome by active ginseng ingredients, the tumor immune microenvironment, and tumor immunotherapeutic effects are unknown and require additional evidence, warranting further research.

In order to improve organ/tumor-site targeting, increase solubility of ginseng active ingredients, and reduce drug toxicity toward non-cancerous cells, researchers have combined nanoscale drug delivery systems with ginsengderived drugs to improve biological activities of ginseng active ingredients for enhanced therapeutic effect. For example, a folic acid-modified targeting-drug delivery system based on bovine serum albumin nanoparticles achieved targeted accumulation of drugs at the cancer focus that significantly increased anti-cancer effectiveness of $\operatorname{Rg} 5$ in breast cancer (Dong et al., 2019). Meanwhile, use of multiple nanoparticle-loaded $\operatorname{Rg} 3$ was shown to achieve good organ targeting, possess sustained release properties, and exert superior anti-cancer activities, while also facilitating transport of drugs across the blood-brain barrier (Qiu et al., 2019; Ren et al., 2020; Su et al., 2020). These results support potential benefits of ginseng ingredients for use in numerous clinical applications.

Although targets of ginseng anti-cancer effects are unknown, it is undeniable that active ingredients of ginseng influence the interaction between the tumor and the TME through several mechanisms: by inhibiting tumor angiogenesis, regulating the immunosuppressive TME, and by inhibiting stemness of cancer stem cells (Figure 3 ). Therefore, use of a combination of ginsenosides and/or polysaccharides as cancer adjuvant therapies to target the TME 
may be a useful anti-tumor therapeutic strategy that may also reduce side effects of chemotherapy or immunotherapy. In addition, the application of red ginseng and white ginseng roots for adjuvant treatment of tumor patients is practical, but the dose must be further standardized and validated using clinical data and the ginseng target network must be further elucidated. In conclusion, this review provides new insights into possible applications of active ingredients of ginseng for achieving TME remodeling.

\section{AUTHOR CONTRIBUTIONS}

ML: Conceptualization, Writing-original draft, Writing-review and editing. LL and SZ: Conceptualization,

\section{REFERENCES}

Abou Khouzam, R., Rao, S. P., Venkatesh, G. H., Zeinelabdin, N. A., Buart, S., Meylan, M., et al. (2021). An Eight-Gene Hypoxia Signature Predicts Survival in Pancreatic Cancer and Is Associated with an Immunosuppressed Tumor Microenvironment. Front. Immunol. 12, 680435. doi:10.3389/ fimmu.2021.680435

Ahuja, A., Kim, J. H., Kim, J. H., Yi, Y. S., and Cho, J. Y. (2018). Functional Role of Ginseng-Derived Compounds in Cancer. J. Ginseng Res. 42 (3), 248-254. doi:10.1016/j.jgr.2017.04.009

Bai, X., Ni, J., Beretov, J., Graham, P., and Li, Y. (2018). Cancer Stem Cell in Breast Cancer Therapeutic Resistance. Cancer Treat. Rev. 69, 152-163. doi:10.1016/ j.ctrv.2018.07.004

Baik, J. S., Seo, Y. N., Yi, J. M., Rhee, M. H., Park, M. T., and Kim, S. D. (2020). Ginsenoside-Rp1 Inhibits Radiation-Induced Effects in LipopolysaccharideStimulated J774A.1 Macrophages and Suppresses Phenotypic Variation in CT26 colon Cancer Cells. J. Ginseng Res. 44 (6), 843-848. doi:10.1016/ j.jgr.2020.01.006

Bandola-Simon, J., and Roche, P. A. (2019). Dysfunction of Antigen Processing and Presentation by Dendritic Cells in Cancer. Mol. Immunol. 113, 31-37. doi:10.1016/j.molimm.2018.03.025

Bergers, G., and Benjamin, L. E. (2003). Tumorigenesis and the Angiogenic Switch. Nat. Rev. Cancer 3 (6), 401-410. doi:10.1038/nrc1093

Bonfim-Silva, R., Souza, L. E., Melo, F. U., Oliveira, V. C., Magalhães, D. A., Oliveira, H. F., et al. (2017). Bone Marrow-Derived Cells Are Recruited by the Melanoma Tumor with Endothelial Cells Contributing to Tumor Vasculature. Clin. Transl Oncol. 19 (1), 125-133. doi:10.1007/s12094-016-1515-Z

Chen, Q. J., Zhang, M. Z., and Wang, L. X. (2010). Gensenoside Rg3 Inhibits Hypoxia-Induced VEGF Expression in Human Cancer Cells. Cell Physiol Biochem 26 (6), 849-858. doi:10.1159/000323994

Chen, Y., Liu, B., Wei, Y., and Kuang, D. M. (2021). Influence of Gut and Intratumoral Microbiota on the Immune Microenvironment and Anticancer Therapy. Pharmacol. Res. 174, 105966. doi:10.1016/ j.phrs.2021.105966

Chen, Y., Zhang, Y., Song, W., Zhang, Y., Dong, X., and Tan, M. (2020). Ginsenoside Rh2 Improves the Cisplatin Anti-tumor Effect in Lung Adenocarcinoma A549 Cells via Superoxide and PD-L1. Anticancer Agents Med. Chem. 20 (4), 495-503. doi:10.2174/1871520619666191209091230

Chen, L., Chen, M. Y., Shao, L., Zhang, W., Rao, T., Zhou, H. H., et al. (2020). Panax Notoginseng Saponins Prevent Colitis-Associated Colorectal Cancer Development: the Role of Gut Microbiota. Chin. J. Nat. Med. 18 (7), 500-507. doi:10.1016/S1875-5364(20)30060-1

Cheng, H., Guan, X., Chen, D., and Ma, W. (2019). The Th17/Treg Cell Balance: A Gut Microbiota-Modulated Story. Microorganisms 7 (12), 583. doi:10.3390/ microorganisms7120583

Cheng, J., Meng, J., Zhu, L., and Peng, Y. (2020). Exosomal Noncoding RNAs in Glioma: Biological Functions and Potential Clinical Applications. Mol. Cancer 19 (1), 66. doi:10.1186/s12943-020-01189-3
Supervision, Funding acquisition, Writing-review and editing. LS: Conceptualization, Supervision, Writing - review and editing. XW, YW, SB, and QC: Writing-review and editing. All authors contributed to the article and approved it for publication.

\section{FUNDING}

This work was supported by the National Natural Science Foundation of China (82104428), Department of Finance of Jilin Province (2020SCZT035) and the Administration of Traditional Chinese Medicine of Jilin Province (No. 2020170).

Choi, H. S., Kim, K. H., Sohn, E., Park, J. D., Kim, B. O., Moon, E. Y., et al. (2008). Red Ginseng Acidic Polysaccharide (RGAP) in Combination with IFN-Gamma Results in Enhanced Macrophage Function through Activation of the NFkappaB Pathway. Biosci. Biotechnol. Biochem. 72 (7), 1817-1825. doi:10.1271/ bbb. 80085

Clara, J. A., Monge, C., Yang, Y., and Takebe, N. (2020). Targeting Signalling Pathways and the Immune Microenvironment of Cancer Stem Cells - a Clinical Update. Nat. Rev. Clin. Oncol. 17 (4), 204-232. doi:10.1038/s41571-019-0293-2

De Almeida, C. V., de Camargo, M. R., Russo, E., and Amedei, A. (2019). Role of Diet and Gut Microbiota on Colorectal Cancer Immunomodulation. World J. Gastroenterol. 25 (2), 151-162. doi:10.3748/wjg.v25.i2.151

Del Prete, A., Sozio, F., Barbazza, I., Salvi, V., Tiberio, L., Laffranchi, M., et al. (2020). Functional Role of Dendritic Cell Subsets in Cancer Progression and Clinical Implications. Int. J. Mol. Sci. 21 (11), 3930. doi:10.3390/ijms21113930

Deng, X., Zhao, J., Qu, L., Duan, Z., Fu, R., Zhu, C., et al. (2020). Ginsenoside Rh4 Suppresses Aerobic Glycolysis and the Expression of PD-L1 via Targeting AKT in Esophageal Cancer. Biochem. Pharmacol. 178, 114038. doi:10.1016/ j.bcp.2020.114038

Dong, Y., Fu, R., Yang, J., Ma, P., Liang, L., Mi, Y., et al. (2019). Folic Acid-Modified Ginsenoside Rg5-Loaded Bovine Serum Albumin Nanoparticles for Targeted Cancer Therapy In Vitro and In Vivo. Int. J. Nanomedicine 14, 6971-6988. doi:10.2147/IJN.S210882

Dong, Y., Han, Y., Huang, Y., Jiang, S., Huang, Z., Chen, R., et al. (2020). PD-L1 Is Expressed and Promotes the Expansion of Regulatory T Cells in Acute Myeloid Leukemia. Front. Immunol. 11, 1710. doi:10.3389/fimmu.2020.01710

Duan, Z., Deng, J., Dong, Y., Zhu, C., Li, W., and Fan, D. (2017). Anticancer Effects of Ginsenoside Rk3 on Non-small Cell Lung Cancer Cells: In Vitro and In Vivo. Food Funct. 8 (10), 3723-3736. doi:10.1039/c7fo00385d

Elkrief, A., Derosa, L., Zitvogel, L., Kroemer, G., and Routy, B. (2019). The Intimate Relationship between Gut Microbiota and Cancer Immunotherapy. Gut Microbes 10 (3), 424-428. doi:10.1080/19490976.2018.1527167

Fu, C., and Jiang, A. (2018). Dendritic Cells and CD8 T Cell Immunity in Tumor Microenvironment. Front. Immunol. 9, 3059. doi:10.3389/fimmu.2018.03059

Ge, X., Zhen, F., Yang, B., Yang, X., Cai, J., Zhang, C., et al. (2014). Ginsenoside Rg3 Enhances Radiosensitization of Hypoxic Oesophageal Cancer Cell Lines through Vascular Endothelial Growth Factor and Hypoxia Inducible Factor 1a. J. Int. Med. Res. 42 (3), 628-640. doi:10.1177/0300060513505491

Gervais, A., Levêque, J., Bouet-Toussaint, F., Burtin, F., Lesimple, T., Sulpice, L., et al. (2005). Dendritic Cells Are Defective in Breast Cancer Patients: a Potential Role for Polyamine in This Immunodeficiency. Breast Cancer Res. 7 (3), R326-R335. doi:10.1186/bcr1001

Gopalakrishnan, V., Spencer, C. N., Nezi, L., Reuben, A., Andrews, M. C., Karpinets, T. V., et al. (2018). Gut Microbiome Modulates Response to Anti-PD-1 Immunotherapy in Melanoma Patients. Science 359 (6371), 97-103. doi:10.1126/science.aan4236

Guo, M., Shao, S., Wang, D., Zhao, D., and Wang, M. (2021). Recent Progress in Polysaccharides from Panax Ginseng C. A. Meyer. Food Funct. 12 (2), 494-518. doi:10.1039/d0fo01896a 
Gupta, R., Bhatt, L. K., Johnston, T. P., and Prabhavalkar, K. S. (2019). Colon Cancer Stem Cells: Potential Target for the Treatment of Colorectal Cancer. Cancer Biol. Ther. 20 (8), 1068-1082. doi:10.1080/15384047.2019.1599660

Hanahan, D., and Folkman, J. (1996). Patterns and Emerging Mechanisms of the Angiogenic Switch during Tumorigenesis. Cell 86 (3), 353-364. doi:10.1016/ s0092-8674(00)80108-7

Hasegawa, H., Suzuki, R., Nagaoka, T., Tezuka, Y., Kadota, S., and Saiki, I. (2002). Prevention of Growth and Metastasis of Murine Melanoma through Enhanced Natural-Killer Cytotoxicity by Fatty Acid-Conjugate of Protopanaxatriol. Biol. Pharm. Bull. 25 (7), 861-866. doi:10.1248/bpb.25.861

Heng, W. S., Gosens, R., and Kruyt, F. A. E. (2019). Lung Cancer Stem Cells: Origin, Features, Maintenance Mechanisms and Therapeutic Targeting. Biochem. Pharmacol. 160, 121-133. doi:10.1016/j.bcp.2018.12.010

Hu, M., Yang, J., Qu, L., Deng, X., Duan, Z., Fu, R., et al. (2020). Ginsenoside Rk1 Induces Apoptosis and Downregulates the Expression of PD-L1 by Targeting the NF-Kb Pathway in Lung Adenocarcinoma. Food Funct. 11 (1), 456-471. doi:10.1039/c9fo02166c

Huang, J., Liu, D., Wang, Y., Liu, L., Li, J., Yuan, J., et al. (2021). Ginseng Polysaccharides Alter the Gut Microbiota and Kynurenine/tryptophan Ratio, Potentiating the Antitumour Effect of Antiprogrammed Cell Death 1/ programmed Cell Death Ligand 1 (Anti-PD-1/PD-L1) Immunotherapy. Gut. doi:10.1136/gutjnl-2020-321031

Jiang, L., Fang, X., Wang, H., Li, D., and Wang, X. (2018). Ovarian Cancer-Intrinsic Fatty Acid Synthase Prevents Anti-tumor Immunity by Disrupting TumorInfiltrating Dendritic Cells. Front. Immunol. 9, 2927. doi:10.3389/ fimmu.2018.02927

Jiang, Z., Yang, Y., Yang, Y., Zhang, Y., Yue, Z., Pan, Z., et al. (2017). Ginsenoside Rg3 Attenuates Cisplatin Resistance in Lung Cancer by Downregulating PD-L1 and Resuming Immune. Biomed. Pharmacother. 96, 378-383. doi:10.1016/ j.biopha.2017.09.129

Kang, A., Hao, H., Zheng, X., Liang, Y., Xie, Y., Xie, T., et al. (2011). Peripheral Anti-inflammatory Effects Explain the Ginsenosides Paradox between Poor Brain Distribution and Anti-depression Efficacy. J. Neuroinflammation 8, 100. doi:10.1186/1742-2094-8-100

Kang, A., Xie, T., Zhu, D., Shan, J., Di, L., and Zheng, X. (2017). Suppressive Effect of Ginsenoside Rg3 against Lipopolysaccharide-Induced Depression-like Behavior and Neuroinflammation in Mice. J. Agric. Food Chem. 65 (32), 6861-6869. doi:10.1021/acs.jafc.7b02386

Kang, J. I., Choi, Y., Cui, C. H., Lee, D., Kim, S. C., and Kim, H. M. (2019). Pro-angiogenic Ginsenosides F1 and Rh1 Inhibit Vascular Leakage by Modulating NR4A1. Sci. Rep. 9 (1), 4502. doi:10.1038/s41598-01941115-2

Kim, D. H. (2018). Gut Microbiota-Mediated Pharmacokinetics of Ginseng Saponins. J. Ginseng Res. 42 (3), 255-263. doi:10.1016/j.jgr.2017.04.011

Kim, H., Choi, P., Kim, T., Kim, Y., Song, B. G., Park, Y. T., et al. (2021). Ginsenosides Rk1 and Rg5 Inhibit Transforming Growth Factor-B1-Induced Epithelial-Mesenchymal Transition and Suppress Migration, Invasion, Anoikis Resistance, and Development of Stem-like Features in Lung Cancer. J. Ginseng Res. 45 (1), 134-148. doi:10.1016/j.jgr.2020.02.005

Kim, H. S., and Seo, H. K. (2018). Immune Checkpoint Inhibitors for Urothelial Carcinoma. Investig. Clin. Urol. 59 (5), 285-296. doi:10.4111/icu.2018.59.5.285

Kim, J., and Bae, J. S. (2016). Tumor-Associated Macrophages and Neutrophils in Tumor Microenvironment. Mediators Inflamm. 2016, 6058147. doi:10.1155/ 2016/6058147

Kim, J. W., Jung, S. Y., Kwon, Y. H., Lee, J. H., Lee, Y. M., Lee, B. Y., et al. (2012a). Ginsenoside Rg3 Attenuates Tumor Angiogenesis via Inhibiting Bioactivities of Endothelial Progenitor Cells. Cancer Biol. Ther. 13 (7), 504-515. doi:10.4161/ cbt.19599

Kim, J. W., Jung, S. Y., Kwon, Y. H., Lee, S. H., Lee, J. H., Lee, B. Y., et al. (2012b). Ginsenoside Rg3 Inhibits Endothelial Progenitor Cell Differentiation through Attenuation of VEGF-dependent Akt/eNOS Signaling. Phytother Res. 26 (9), 1286-1293. doi:10.1002/ptr.3722

Krishna Priya, S., Nagare, R. P., Sneha, V. S., Sidhanth, C., Bindhya, S., Manasa, P., et al. (2016). Tumour Angiogenesis-Origin of Blood Vessels. Int. J. Cancer 139 (4), 729-735. doi:10.1002/ijc.30067

Kwon, H. J., Lee, H., Choi, G. E., Kwon, S. J., Song, A. Y., Kim, S. J., et al. (2018). Ginsenoside F1 Promotes Cytotoxic Activity of NK Cells via Insulin-like
Growth Factor-1-dependent Mechanism. Front. Immunol. 9, 2785. doi:10.3389/fimmu.2018.02785

Lee, D. Y., Park, C. W., Lee, S. J., Park, H. R., Kim, S. H., Son, S. U., et al. (2019a). Anti-Cancer Effects of Panax Ginseng Berry Polysaccharides via Activation of Immune-Related Cells. Front. Pharmacol. 10, 1411. doi:10.3389/ fphar.2019.01411

Lee, D. Y., Park, C. W., Lee, S. J., Park, H. R., Seo, D. B., Park, J. Y., et al. (2019b). Immunostimulating and Antimetastatic Effects of Polysaccharides Purified from Ginseng Berry. Am. J. Chin. Med. 47 (4), 823-839. doi:10.1142/ S0192415X19500435

Lee, S. Y., Yuk, H. G., Ko, S. G., Cho, S.-G., and Moon, G.-S. (2021). Gut Microbiome Prolongs an Inhibitory Effect of Korean Red Ginseng on HighFat-Diet-Induced Mouse Obesity. Nutrients 13 (3), 926. doi:10.3390/ nu13030926

Legitimo, A., Consolini, R., Failli, A., Orsini, G., and Spisni, R. (2014). Dendritic Cell Defects in the Colorectal Cancer. Hum. Vaccin. Immunother. 10 (11), 3224-3235. doi:10.4161/hv.29857

Lei, X., Lei, Y., Li, J. K., Du, W. X., Li, R. G., Yang, J., et al. (2020). Immune Cells within the Tumor Microenvironment: Biological Functions and Roles in Cancer Immunotherapy. Cancer Lett. 470, 126-133. doi:10.1016/j.canlet.2019.11.009

Li, B., and Qu, G. (2019). Inhibition of the Hypoxia-Induced Factor-1 $\alpha$ and Vascular Endothelial Growth Factor Expression through Ginsenoside Rg3 in Human Gastric Cancer Cells. J. Cancer Res. Ther. 15 (7), 1642-1646. doi:10.4103/jcrt.JCRT_77_17

Li, H., Huang, N., Zhu, W., Wu, J., Yang, X., Teng, W., et al. (2018). Modulation the Crosstalk between Tumor-Associated Macrophages and Non-small Cell Lung Cancer to Inhibit Tumor Migration and Invasion by Ginsenoside Rh2. BMC cancer 18 (1), 579. doi:10.1186/s12885-018-4299-4

Li, J., Li, R., Li, N., Zheng, F., Dai, Y., Ge, Y., et al. (2018). Mechanism of Antidiabetic and Synergistic Effects of Ginseng Polysaccharide and Ginsenoside Rb1 on Diabetic Rat Model. J. Pharm. Biomed. Anal. 158, 451-460. doi:10.1016/j.jpba.2018.06.024

Li, X., Chu, S., Lin, M., Gao, Y., Liu, Y., Yang, S., et al. (2020). Anticancer Property of Ginsenoside Rh2 from Ginseng. Eur. J. Med. Chem. 203, 112627. doi:10.1016/ j.ejmech.2020.112627

Li, W., Peng, A., Wu, H., Quan, Y., Li, Y., Lu, L., et al. (2020). Anti-Cancer Nanomedicines: A Revolution of Tumor Immunotherapy. Front. Immunol. 11, 601497. doi:10.3389/fimmu.2020.601497

Li, Q., Jin, M., Liu, Y., and Jin, L. (2020). Gut Microbiota: Its Potential Roles in Pancreatic Cancer. Front Cel Infect Microbiol 10, 572492. doi:10.3389/ fcimb.2020.572492

Liskova, A., Koklesova, L., Samec, M., Smejkal, K., Samuel, S. M., Varghese, E., et al. (2020). Flavonoids in Cancer Metastasis. Cancers (Basel) 12 (6), 1498. doi:10.3390/cancers 12061498

Löb, S., Königsrainer, A., Rammensee, H.-G., Opelz, G., and Terness, P. (2009). Inhibitors of Indoleamine-2,3-Dioxygenase for Cancer Therapy: Can We See the wood for the Trees. Nat. Rev. Cancer 9 (6), 445-452. doi:10.1038/nrc2639

Looi, C. K., Chung, F. F., Leong, C. O., Wong, S. F., Rosli, R., and Mai, C. W. (2019). Therapeutic Challenges and Current Immunomodulatory Strategies in Targeting the Immunosuppressive Pancreatic Tumor Microenvironment. J. Exp. Clin. Cancer Res. 38 (1), 162. doi:10.1186/s13046-019-1153-8

López de Andrés, J., Griñán-Lisón, C., Jiménez, G., and Marchal, J. A. (2020). Cancer Stem Cell Secretome in the Tumor Microenvironment: a Key point for an Effective Personalized Cancer Treatment. J. Hematol. Oncol. 13 (1), 136. doi:10.1186/s13045-020-00966-3

Lu, H., Zhou, X., Kwok, H. H., Dong, M., Liu, Z., Poon, P. Y., et al. (2017). Ginsenoside-Rb1-Mediated Anti-angiogenesis via Regulating PEDF and miR33a through the Activation of PPAR- $\gamma$ Pathway. Front. Pharmacol. 8, 783. doi:10.3389/fphar.2017.00783

Lugano, R., Ramachandran, M., and Dimberg, A. (2020). Tumor Angiogenesis: Causes, Consequences, Challenges and Opportunities. Cell Mol Life Sci 77 (9), 1745-1770. doi:10.1007/s00018-019-03351-7

Luo, X., Wang, H., and Ji, D. (2021). Carbon Nanotubes (CNT)-loaded Ginsenosides Rb3 Suppresses the PD-1/pd-L1 Pathway in Triple-Negative Breast Cancer. Aging 13, 17177-17189. doi:10.18632/aging.203131

Ma, J., Liu, H., and Wang, X. (2014). Effect of Ginseng Polysaccharides and Dendritic Cells on the Balance of Th1/Th2 T Helper Cells in Patients with Non- 
small Cell Lung Cancer. J. Tradit Chin. Med. 34 (6), 641-645. doi:10.1016/ s0254-6272(15)30076-5

Meng, J., Meng, Y., Liang, Z., Du, L., Zhang, Z., Hu, X., et al. (2013). Phenotypic and Functional Analysis of the Modification of Murine Bone Marrow Dendritic Cells (BMDCs) Induced by Neutral Ginseng Polysaccharides (NGP). Hum. Vaccin. Immunother. 9 (2), 233-241. doi:10.4161/hv.22612

Meng, L., Ji, R., Dong, X., Xu, X., Xin, Y., and Jiang, X. (2019). Antitumor Activity of Ginsenoside Rg3 in Melanoma through Downregulation of the ERK and Akt Pathways. Int. J. Oncol. 54 (6), 2069-2079. doi:10.3892/ ijo.2019.4787

Meurette, O., and Mehlen, P. (2018). Notch Signaling in the Tumor Microenvironment. Cancer Cell 34 (4), 536-548. doi:10.1016/j.ccell.2018.07.009

Mo, C., Xie, S., Zeng, T., Lai, Y., Huang, S., Zhou, C., et al. (2021). Ginsenoside-Rg1 Acts as an Ido1 Inhibitor, Protects against Liver Fibrosis via Alleviating Ido1mediated the Inhibition of DCs Maturation. Phytomedicine 84, 153524. doi:10.1016/j.phymed.2021.153524

Munn, D. H., and Mellor, A. L. (2016). Ido in the Tumor Microenvironment: Inflammation, Counter-regulation, and Tolerance. Trends Immunol. 37 (3), 193-207. doi:10.1016/j.it.2016.01.002

Nelson, M. H., Diven, M. A., Huff, L. W., and Paulos, C. M. (2015). Harnessing the Microbiome to Enhance Cancer Immunotherapy. J. Immunol. Res. 2015, 368736. doi:10.1155/2015/368736

Ni, W., Zhang, X., Wang, B., Chen, Y., Han, H., Fan, Y., et al. (2010). Antitumor Activities and Immunomodulatory Effects of Ginseng Neutral Polysaccharides in Combination with 5-fluorouracil. J. Med. Food 13 (2), 270-277. doi:10.1089/ jmf.2009.1119

Nolan, D. J., Ciarrocchi, A., Mellick, A. S., Jaggi, J. S., Bambino, K., Gupta, S., et al. (2007). Bone Marrow-Derived Endothelial Progenitor Cells Are a Major Determinant of Nascent Tumor Neovascularization. Genes Dev. 21 (12), 1546-1558. doi:10.1101/gad.436307

Oh, H. K., Ha, J. M., Eunju, O., Lee, S. K., Shim, B. S., Hong, Y. K., et al. (2007). Tumor Angiogenesis Promoted by Ex Vivo Differentiated Endothelial Progenitor Cells Is Effectively Inhibited by an Angiogenesis Inhibitor, TK12. Cancer Res. 67 (10), 4851-4859. doi:10.1158/0008-5472.Can-06-2979

Oh, J., Jeon, S. B., Lee, Y., Lee, H., Kim, J., Kwon, B. R., et al. (2015). Fermented Red Ginseng Extract Inhibits Cancer Cell Proliferation and Viability. J. Med. Food 18 (4), 421-428. doi:10.1089/jmf.2014.3248

Oh, J., Yoon, H. J., Jang, J. H., Kim, D. H., and Surh, Y. J. (2019). The Standardized Korean Red Ginseng Extract and its Ingredient Ginsenoside Rg3 Inhibit Manifestation of Breast Cancer Stem Cell-like Properties through Modulation of Self-Renewal Signaling. J. Ginseng Res. 43 (3), 421-430. doi:10.1016/j.jgr.2018.05.004

Ohno, H. (2020). The Impact of Metabolites Derived from the Gut Microbiota on Immune Regulation and Diseases. Int. Immunol. 32 (10), 629-636. doi:10.1093/ intimm/dxaa041

Park, J. W., Park, J. H., and Han, J. W. (2020). Fermented Ginseng Extract, BST204, Suppresses Tumorigenesis and Migration of Embryonic Carcinoma through Inhibition of Cancer Stem Cell Properties. Molecules 25 (14), 3128. doi:10.3390/ molecules 25143128

Peng, S., Wang, R., Zhang, X., Ma, Y., Zhong, L., Li, K., et al. (2019). EGFR-TKI Resistance Promotes Immune Escape in Lung Cancer via Increased PD-L1 Expression. Mol. Cancer 18 (1), 165. doi:10.1186/s12943-019-1073-4

Phi, L. T. H., Wijaya, Y. T., Sari, I. N., Kim, K. S., Yang, Y. G., Lee, M. W., et al. (2019a). 20(R)-Ginsenoside Rg3 Influences Cancer Stem Cell Properties and the Epithelial-Mesenchymal Transition in Colorectal Cancer via the SNAIL Signaling Axis. Onco Targets Ther. 12, 10885-10895. doi:10.2147/OTT.S219063

Phi, L. T. H., Sari, I. N., Wijaya, Y. T., Kim, K. S., Park, K., Cho, A. E., et al. (2019b). Ginsenoside Rd Inhibits the Metastasis of Colorectal Cancer via Epidermal Growth Factor Receptor Signaling Axis. IUBMB Life 71 (5), 601-610. doi:10.1002/iub.1984

Pitt, J. M., Marabelle, A., Eggermont, A., Soria, J. C., Kroemer, G., and Zitvogel, L. (2016). Targeting the Tumor Microenvironment: Removing Obstruction to Anticancer Immune Responses and Immunotherapy. Ann. Oncol. 27 (8), 1482-1492. doi:10.1093/annonc/mdw168

Plummer, P. N., Freeman, R., Taft, R. J., Vider, J., Sax, M., Umer, B. A., et al. (2013). MicroRNAs Regulate Tumor Angiogenesis Modulated by Endothelial Progenitor Cells. Cancer Res. 73 (1), 341-352. doi:10.1158/0008-5472.Can$12-0271$
Qi, H., Zhang, Z., Liu, J., Chen, Z., Huang, Q., Li, J., et al. (2021). Comparisons of Isolation Methods, Structural Features, and Bioactivities of the Polysaccharides from Three Common Panax Species: A Review of Recent Progress. Molecules 26 (16), 4997. doi:10.3390/molecules26164997

Qiu, R., Qian, F., Wang, X., Li, H., and Wang, L. (2019). Targeted Delivery of 20(S)ginsenoside Rg3-Based Polypeptide Nanoparticles to Treat colon Cancer. Biomed. Microdevices 21 (1), 18. doi:10.1007/s10544-019-0374-0

Qu, Q., Yang, F., Zhao, C., Liu, X., Yang, P., Li, Z., et al. (2021). Effects of Fermented Ginseng on the Gut Microbiota and Immunity of Rats with AntibioticAssociated Diarrhea. J. Ethnopharmacol 267, 113594. doi:10.1016/ j.jep.2020.113594

Ren, Z., Chen, X., Hong, L., Zhao, X., Cui, G., Li, A., et al. (2020). Nanoparticle Conjugation of Ginsenoside Rg3 Inhibits Hepatocellular Carcinoma Development and Metastasis. Small 16 (2), e1905233. doi:10.1002/ smll.201905233

Ribatti, D., and Tamma, R. (2019). Hematopoietic Growth Factors and Tumor Angiogenesis. Cancer Lett. 440-441, 47-53. doi:10.1016/ j.canlet.2018.10.008

Rooks, M. G., and Garrett, W. S. (2016). Gut Microbiota, Metabolites and Host Immunity. Nat. Rev. Immunol. 16 (6), 341-352. doi:10.1038/nri.2016.42

Round, J. L., and Mazmanian, S. K. (2010). Inducible Foxp3+ Regulatory T-Cell Development by a Commensal Bacterium of the Intestinal Microbiota. Proc. Natl. Acad. Sci. U S A. 107 (27), 12204-12209. doi:10.1073/pnas.0909122107

Routy, B., Le Chatelier, E., Derosa, L., Duong, C. P. M., Alou, M. T., Daillère, R., et al. (2018). Gut Microbiome Influences Efficacy of PD-1-Based Immunotherapy against Epithelial Tumors. Science 359 (6371), 91-97. doi:10.1126/science.aan3706

Sharma, M. D., Hou, D. Y., Baban, B., Koni, P. A., He, Y., Chandler, P. R., et al. (2010). Reprogrammed Foxp3(+) Regulatory T Cells Provide Essential Help to Support Cross-Presentation and CD8(+) T Cell Priming in Naive Mice. Immunity 33 (6), 942-954. doi:10.1016/j.immuni.2010.11.022

Shen, M., Xu, Z., Xu, W., Jiang, K., Zhang, F., Ding, Q., et al. (2019). Inhibition of ATM Reverses EMT and Decreases Metastatic Potential of Cisplatin-Resistant Lung Cancer Cells through JAK/STAT3/PD-L1 Pathway. J. Exp. Clin. Cancer Res. 38 (1), 149. doi:10.1186/s13046-019-1161-8

Shibuya, M. (2013). Vascular Endothelial Growth Factor and its Receptor System: Physiological Functions in Angiogenesis and Pathological Roles in Various Diseases. J. Biochem. 153 (1), 13-19. doi:10.1093/jb/mvs136

Shin, M. S., Hwang, S. H., Yoon, T. J., Kim, S. H., and Shin, K. S. (2017). Polysaccharides from Ginseng Leaves Inhibit Tumor Metastasis via Macrophage and NK Cell Activation. Int. J. Biol. Macromol 103, 1327-1333. doi:10.1016/j.ijbiomac.2017.05.055

Shin, M. S., Song, J. H., Choi, P., Lee, J. H., Kim, S. Y., Shin, K. S., et al. (2018). Stimulation of Innate Immune Function by Panax Ginseng after Heat Processing. J. Agric. Food Chem. 66 (18), 4652-4659. doi:10.1021/ acs.jafc. 8 b00152

Singh, S. K., Clarke, I. D., Terasaki, M., Bonn, V. E., Hawkins, C., Squire, J., et al. (2003). Identification of a Cancer Stem Cell in Human Brain Tumors. Cancer Res. 63 (18), 5821-5828.

Son, K. J., Choi, K. R., Lee, S. J., and Lee, H. (2016). Immunogenic Cell Death Induced by Ginsenoside Rg3: Significance in Dendritic Cell-Based Anti-tumor Immunotherapy. Immune Netw. 16 (1), 75-84. doi:10.4110/in.2016.16.1.75

Song, M. Y., Kim, B. S., and Kim, H. (2014). Influence of Panax Ginseng on Obesity and Gut Microbiota in Obese Middle-Aged Korean Women. J. Ginseng Res. 38 (2), 106-115. doi:10.1016/j.jgr.2013.12.004

Su, X., Zhang, D., Zhang, H., Zhao, K., and Hou, W. (2020). Preparation and Characterization of Angiopep-2 Functionalized Ginsenoside-Rg3 Loaded Nanoparticles and the Effect on C6 Glioma Cells. Pharm. Dev. Technol. 25 (3), 385-395. doi:10.1080/10837450.2018.1551901

Sun, M., Ye, Y., Xiao, L., Duan, X., Zhang, Y., and Zhang, H. (2017). Anticancer Effects of Ginsenoside Rg3 (Review). Int. J. Mol. Med. 39 (3), 507-518. doi:10.3892/ijmm.2017.2857

Takei, M., Tachikawa, E., Hasegawa, H., and Lee, J. J. (2004). Dendritic Cells Maturation Promoted by M1 and M4, End Products of Steroidal Ginseng Saponins Metabolized in Digestive Tracts, Drive a Potent Th1 Polarization. Biochem. Pharmacol. 68 (3), 441-452. doi:10.1016/j.bcp.2004.04.015

Tan, Q., Lin, S., Zeng, Y., Yao, M., Liu, K., Yuan, H., et al. (2020). Ginsenoside Rg3 Attenuates the Osimertinib Resistance by Reducing the Stemness of Non-small 
Cell Lung Cancer Cells. Environ. Toxicol. 35 (6), 643-651. doi:10.1002/ tox.22899

Tang, C., Wang, X., Soh, H., Seyedin, S., Cortez, M. A., Krishnan, S., et al. (2014). Combining Radiation and Immunotherapy: a New Systemic Therapy for Solid Tumors. Cancer Immunol. Res. 2 (9), 831-838. doi:10.1158/2326-6066.Cir-140069

Tang, Y. C., Zhang, Y., Zhou, J., Zhi, Q., Wu, M. Y., Gong, F. R., et al. (2018). Ginsenoside Rg3 Targets Cancer Stem Cells and Tumor Angiogenesis to Inhibit Colorectal Cancer Progression In Vivo. Int. J. Oncol. 52 (1), 127-138. doi:10.3892/ijo.2017.4183

Untersmayr, E., Bax, H. J., Bergmann, C., Bianchini, R., Cozen, W., Gould, H. J., et al. (2019). AllergoOncology: Microbiota in Allergy and Cancer-A European Academy for Allergy and Clinical Immunology Position Paper. Allergy 74 (6), 1037-1051. doi:10.1111/all.13718

Uribe-Herranz, M., Bittinger, K., Rafail, S., Guedan, S., Pierini, S., Tanes, C., et al. (2018). Gut Microbiota Modulates Adoptive Cell Therapy via CD8a Dendritic Cells and IL-12. JCI Insight 3 (4), e94952. doi:10.1172/jci.insight.94952

Uyttenhove, C., Pilotte, L., Théate, I., Stroobant, V., Colau, D., Parmentier, N., et al. (2003). Evidence for a Tumoral Immune Resistance Mechanism Based on Tryptophan Degradation by Indoleamine 2,3-dioxygenase. Nat. Med. 9 (10), 1269-1274. doi:10.1038/nm934

Vétizou, M., Pitt, J. M., Daillère, R., Lepage, P., Waldschmitt, N., Flament, C., et al. (2015). Anticancer Immunotherapy by CTLA-4 Blockade Relies on the Gut Microbiota. Science 350 (6264), 1079-1084. doi:10.1126/science.aad1329

Viallard, C., and Larrivée, B. (2017). Tumor Angiogenesis and Vascular Normalization: Alternative Therapeutic Targets. Angiogenesis 20 (4), 409-426. doi:10.1007/s10456-017-9562-9

Viaud, S., Saccheri, F., Mignot, G., Yamazaki, T., Daillère, R., Hannani, D., et al. (2013). The Intestinal Microbiota Modulates the Anticancer Immune Effects of Cyclophosphamide. Science 342 (6161), 971-976. doi:10.1126/science.1240537

Walcher, L., Kistenmacher, A. K., Suo, H., Kitte, R., Dluczek, S., Strauß, A., et al. (2020). Cancer Stem Cells-Origins and Biomarkers: Perspectives for Targeted Personalized Therapies. Front. Immunol. 11, 1280. doi:10.3389/ fimmu.2020.01280

Wang, C. Z., Hou, L., Wan, J. Y., Yao, H., Yuan, J., Zeng, J., et al. (2020). Ginseng berry Polysaccharides on Inflammation-Associated colon Cancer: Inhibiting T-Cell Differentiation, Promoting Apoptosis, and Enhancing the Effects of 5fluorouracil. J. Ginseng Res. 44 (2), 282-290. doi:10.1016/j.jgr.2018.12.010

Wang, C. Z., Yu, C., Wen, X. D., Chen, L., Zhang, C. F., Calway, T., et al. (2016). American Ginseng Attenuates Colitis-Associated Colon Carcinogenesis in Mice: Impact on Gut Microbiota and Metabolomics. Cancer Prev. Res. (Phila) 9 (10), 803-811. doi:10.1158/1940-6207.CAPR-15-0372

Wang, J., Tian, L., Khan, M. N., Zhang, L., Chen, Q., Zhao, Y., et al. (2018). Ginsenoside Rg3 Sensitizes Hypoxic Lung Cancer Cells to Cisplatin via Blocking of NF-Kb Mediated Epithelial-Mesenchymal Transition and Stemness. Cancer Lett. 415, 73-85. doi:10.1016/j.canlet.2017.11.037

Wang, X., Mao, J., Zhou, T., Chen, X., Tu, H., Ma, J., et al. (2021). Hypoxia-induced Myeloid Derived Growth Factor Promotes Hepatocellular Carcinoma Progression through Remodeling Tumor Microenvironment. Theranostics 11 (1), 209-221. doi:10.7150/thno.49327

Wang, Y., Huang, M., Sun, R., and Pan, L. (2015). Extraction, Characterization of a Ginseng Fruits Polysaccharide and its Immune Modulating Activities in Rats with Lewis Lung Carcinoma. Carbohydr. Polym. 127, 215-221. doi:10.1016/ j.carbpol.2015.03.070

Wang, X., Xia, H. Y., Qin, H. Y., Kang, X. P., Hu, H. Y., Zheng, J., et al. (2019). 20(S)-protopanaxadiol Induces Apoptosis in Human Umbilical Vein Endothelial Cells by Activating the PERK-eIF2alpha-ATF4 Signaling Pathway. J. Cel Biochem 120 (4), 5085-5096. doi:10.1002/jcb.27785

Wang, Y., Smith, W., Hao, D., He, B., and Kong, L. (2019). M1 and M2 Macrophage Polarization and Potentially Therapeutic Naturally Occurring Compounds. Int. Immunopharmacol 70, 459-466. doi:10.1016/j.intimp.2019.02.050

Wang, Z., Meng, J., Xia, Y., Meng, Y., Du, L., Zhang, Z., et al. (2013). Maturation of Murine Bone Marrow Dendritic Cells Induced by Acidic Ginseng Polysaccharides. Int. J. Biol. Macromol 53, 93-100. doi:10.1016/ j.ijbiomac.2012.11.009
Weis, S. M., and Cheresh, D. A. (2005). Pathophysiological Consequences of VEGF-Induced Vascular Permeability. Nature 437 (7058), 497-504. doi:10.1038/nature03987

Weis, S. M., and Cheresh, D. A. (2011). Tumor Angiogenesis: Molecular Pathways and Therapeutic Targets. Nat. Med. 17 (11), 1359-1370. doi:10.1038/nm.2537

Wu, L., Cai, S., Deng, Y., Zhang, Z., Zhou, X., Su, Y., et al. (2021). PD-1/PD-L1 Enhanced Cisplatin Resistance in Gastric Cancer through PI3K/AKT Mediated P-Gp Expression. Int. Immunopharmacol 94, 107443. doi:10.1016/ j.intimp.2021.107443

Xu, H., Wang, E., Chen, F., Xiao, J., and Wang, M. (2021). Neuroprotective Phytochemicals in Experimental Ischemic Stroke: Mechanisms and Potential Clinical Applications. Oxid Med. Cel Longev 2021, 6687386. doi:10.1155/2021/ 6687386

Xu, J., Li, T., Xia, X., Fu, C., Wang, X., and Zhao, Y. (2020). Dietary Ginsenoside T19 Supplementation Regulates Glucose and Lipid Metabolism via AMPK and PI3K Pathways and its Effect on Intestinal Microbiota. J. Agric. Food Chem. 68 (49), 14452-14462. doi:10.1021/acs.jafc.0c04429

Xu, W. W., Li, B., Guan, X. Y., Chung, S. K., Wang, Y., Yip, Y. L., et al. (2017). Cancer Cell-Secreted IGF2 Instigates Fibroblasts and Bone Marrow-Derived Vascular Progenitor Cells to Promote Cancer Progression. Nat. Commun. 8, 14399. doi:10.1038/ncomms14399

Yim, N. H., Kim, Y. S., and Chung, H. S. (2020). Inhibition of Programmed Death Receptor-1/Programmed Death Ligand-1 Interactions by Ginsenoside Metabolites. Molecules 25 (9), 2068. doi:10.3390/molecules25092068

Zeng, P., Li, J., Chen, Y., and Zhang, L. (2019). The Structures and Biological Functions of Polysaccharides from Traditional Chinese Herbs. Prog. Mol. Biol. Transl Sci. 163, 423-444. doi:10.1016/bs.pmbts.2019.03.003

Zhang, B. P., Li, B., Cheng, J. Y., Cao, R., Gao, S. T., Huang, C. J., et al. (2020). Anticancer Effect of 20(S)-Ginsenoside-Rh2 on Oral Squamous Cell Carcinoma Cells via the Decrease in ROS and Downregulation of MMP-2 and VEGF. Biomed. Environ. Sci. 33 (9), 713-717. doi:10.3967/bes2020.093

Zhang, E., Shi, H., Yang, L., Wu, X., and Wang, Z. (2017). Ginsenoside Rd Regulates the Akt/mTOR/p70S6K Signaling cascade and Suppresses Angiogenesis and Breast Tumor Growth. Oncol. Rep. 38 (1), 359-367. doi:10.3892/or.2017.5652

Zhang, W., Cho, S. Y., Xiang, G., Min, K. J., Yu, Q., and Jin, J. O. (2015). Ginseng Berry Extract Promotes Maturation of Mouse Dendritic Cells. PloS one 10 (6), e0130926. doi:10.1371/journal.pone.0130926

Zhang, Z., Zeng, P., Gao, W., Zhou, Q., Feng, T., and Tian, X. (2021). Circadian Clock: a Regulator of the Immunity in Cancer. Cell Commun Signal 19 (1), 37. doi:10.1186/s12964-021-00721-2

Zheng, S. W., Xiao, S. Y., Wang, J., Hou, W., and Wang, Y. P. (2019). Inhibitory Effects of Ginsenoside Ro on the Growth of B16F10 Melanoma via its Metabolites. Molecules 24 (16), 2985. doi:10.3390/molecules24162985

Zhu, Y., Liang, J., Gao, C., Wang, A., Xia, J., Hong, C., et al. (2021). Multifunctional Ginsenoside Rg3-Based Liposomes for Glioma Targeting Therapy. J. Controlled Release 330, 641-657. doi:10.1016/j.jconrel.2020.12.036

Conflict of Interest: The authors declare that the research was conducted in the absence of any commercial or financial relationships that could be construed as a potential conflict of interest.

Publisher's Note: All claims expressed in this article are solely those of the authors and do not necessarily represent those of their affiliated organizations, or those of the publisher, the editors and the reviewers. Any product that may be evaluated in this article, or claim that may be made by its manufacturer, is not guaranteed or endorsed by the publisher.

Copyright $\odot 2021$ Li, Wang, Wang, Bao, Chang, Liu, Zhang and Sun. This is an open-access article distributed under the terms of the Creative Commons Attribution License (CC BY). The use, distribution or reproduction in other forums is permitted, provided the original author(s) and the copyright owner(s) are credited and that the original publication in this journal is cited, in accordance with accepted academic practice. No use, distribution or reproduction is permitted which does not comply with these terms. 